\title{
Trophic conditions of marine coastal waters: experience in applying the Trophic Index TRIX to two areas of the Adriatic and Tyrrhenian seas
}

\author{
Franco GIOVANARDI* and Richard A. VOLLENWEIDER ${ }^{1)}$ \\ ICRAM - Central Institute for Marine Research, via di Casalotti, 300, 00166 Roma, Italy \\ ${ }^{1)}$ National Water Research Institute, CCIW, Burlington, Ontario, Canada. Senior Scientist Emeritus \\ Private: 262, Townsend Ave., Burlington, Ontario, Canada \\ *e-mail corresponding author: f.giovanardi@icram.org
}

\begin{abstract}
This paper is an extension of an earlier paper on a Trophic Index TRIX, a linear combination of the log of 4 state variables: $C h A, a D \% O, \operatorname{minN} \& T P$ (Vollenweider et al. 1998), to characterizing succinctly the trophic levels of coastal marine areas, and to discuss questions that since have arisen in applying and developing the index further. This entails in depth review of some procedural aspects such as data processing including transformation of rough data; the statistical distribution of TRIX; comparisons over different spatial and temporal scales; discrimination limits between two contiguous means of TRIX; interrelationships between TRIX and its components, and between TRIX and other water related variables. Further to statistical properties of TRIX, attention is given to integrative features and other implicit functional relationships pertinent to the description of trophic characteristics of coastal systems, among which to mention the term "efficiency". This theoretical framework has been applied to data from two trophically different responding coastal systems, i.e. the Emilia-Romagna coastal area of the Adriatic Sea and the Tuscany coastal area of the Tyrrhenian Sea to illustrate some of the arising interpretative problems in using TRIX. Finally, analyses of the two system are juxtaposed in an alternatively slightly modified reference diagram in which the trophic location and the extent of variability are shown in relation to the N/P ratio and related efficiency.
\end{abstract}

Key words: Coastal eutrophication, trophic indicators, Trophic Index, trophic classification criteria, nutrient limitation, efficiency

\section{INTRODUCTION}

According to the E.C. Water Framework Directive (2000/60/E.C.), the prevailing trend in the environmental legislation and regulations is actually oriented to the definition of "ecological and chemical status and ecological potential" of bodies of water.

The use of appropriate environmental quality models, with related judgement criteria, results then essential in assessing water quality and to establish possible quality objectives for a given aquatic environment, coastal areas included. As to the present status of affairs, it is worth to recall that, despite of manifold studies all over the world, sufficient scientific knowledge has been gained to-date essentially only in a few areas of major concern, notably with respect to the problem of eutrophication of lakes and estuaries, and with this the scientific and practical tools pertain to their proper management, restoration and prevention from further deterioration. The basis for this advance was that practice could rely on, and build on the scientific knowledge accumulated over decades in lake research, limnology, which now provides a solid conceptual understanding of how lakes function as ecosystems. In other areas of water quality concern, in particular regarding the raving pollution from xenobiotic compounds, science and practice still struggle to attain not only the necessary knowledge, compound by compound, but to realize a corresponding conceptual framework to be able to decidedly establish what kind, and how much of xenobiotic loads are permissible in any given situation, to avoid serious long term damages to aquatic ecosystem, and their utilization by men.

In eutrophication research an essential breakthrough came with Vollenweider's 1968 OECD Report followed by the OECD International Programme on Eutrophication (OECD, Vollenweider \& Kerekes (Eds) 1982), with regard to two fundamental interrogatories:

- in putting the relationship between nutrient load from all sources, in particular phosphorus and nitrogen, and the respective trophic responses of the receiving bodies of water on a solid quantitative footing, this permitted to give a first try to defining levels of loading tolerance (Vollenweider 1976);

- in attaching quantitative figures, though still tentatively, to long established classic limnological trophic categories (ultra-oligotrophic, oligotrophic, mesotrophic, eutrophic and hypertrophic).

The initial success of the OECD methodology resides in the fact that the judgment criteria were based on a few parameters considered essential, and with regard to the trophic categorisation that the concept of a fixed yet artificially rigid boundary system was widened to an open boundary probabilistic system that is more in tone with the reality. While these tenets though still in evolution (cfr. e.g., Reynolds \& Maberly 2002) are congruous with the behaviour of bodies of waters that in some 
respects are "confined" like lakes and therefore may be treated as "individuals"(1), their unchecked transfer to unconfined (open) coastal marine areas, even to estuaries is more questionable.

Though the principles governing coastal marine eutrophication are the same as for the lakes, there are conditions that are at variance that cannot be ignored. E.g. Jaworsky (1979) and Lee \& Jones (1979) had not negligible difficulty to evaluate variations in concentration of nutrients along the major axis of estuaries and to calculate the residence time of waters in the estuarine zone. Also, applying the OECD methodology to characterize the trophic conditions of the NW Adriatic coastal area, Giovanardi \& Tromellini (1992a) noted that the unqualified extension of limnological criteria to a coastal system presents inherent limitation that are not simply accountable to difference in salinity and biology between marine and fresh waters. The problem with simple transfer of the OECD methodology to the same marine area was further pursued by Zurlini (1996).

Simplifying matters, one of the essential distinction between lakes of moderate size and marine area is the fact that lakes, in very broad terms, can be considered as wholistic entities showing in general rather modest horizontal yet more or less vertical differentiations subject to seasonal cycles. Therefore, also the classic trophic terminology is often applied to a lake as a whole. Marine coastal areas, on the other hand, particularly if they are under the influence of a major river, and/or numerous minor rivers, canals and ports, the physical and chemical-biological characteristics, due to fluctuating freshwater supply, intermittent longitudinal currents and inshore-offshore water exchanges, and variable weather and wind conditions, etc. vary spatially and temporally at scales of kilometres and of days to weeks, respectively, which is clearly the case in the Northern Adriatic Sea (Vollenweider et al. 1992).

With these prerequisites Vollenweider et al. (1998) came to the conclusion that for coastal marine areas of this kind "... a purely numeric scale that scores the trophic properties of surface and subsurface seawaters, station by station and/or sequential in time, would be preferable to some preconceived categorical denominators." Such an approach would open the way to a more realistic, gradient and variance emphasizing, to say rather probabilistic description of the facts, and therefore avoid the pitfall to labelling a coastal area as it were a quasi static entity. Clearly this definition is limitative in the sense that it provides only one facet, while the broad array of tropho-dynamic processes and the related biological diversities that characterize any coastal area, will have to be added by appropriate research. On the other hand, the approach is general, not geographically bound, but on which the mentioned arrays can be built as a platform.
A Trophic Index (TRIX) was then proposed; it is defined by a linear combination of the logarithms of four state variables: chlorophyll- $a$ (ChA), Oxygen as absolute percent deviation from saturation $(\mathrm{aD} \% \mathrm{O})$, mineral nitrogen $(\operatorname{minN})$ and total phosphorus (TP). This Index has been adopted by the Italian national legislation, in the frame of the monitoring activities requested to control coastal marine environment.

As an index-variable, distributions of TRIX data points may be analysed similarly to those of any variable statistically distributed. There have been several references (e.g., Green 1979), on the advantages resulting from the use of an index-variable; in a general sense it can be defined as "a mathematical combination of two or more parameters which has utility at least in an interpretative sense" and this agrees with the necessity of reducing the complexity of the biological systems. This mathematical combination is often represented by a ratio, usually aimed at standardising and relativizing the original variables. Several Diversity Indices currently in use, are applied in the form of a ratio. These procedures are not exempted from risks, that include (Sokal 1973): a) strong increase of variability and heterogeneity of the ratio-variables, compared with the single original variables; b) biased estimation of the true mean value of the ratios; c) probability distributions of the ratio-variables far away from the normality, unusual and practically intractable.

More recent advances in Applied Ecology consider different approaches that recall the econometric techniques. Multimetric indices, formulated as an array of metrics, each of them providing information about a single attribute of the system, have been introduced (Barbour et al. 1995). When single metrics are combined, the derived index works as an overall indicator of the quality of an ecosystem, with respect to the reference situation of absence or negligible presence of environmental stresses (Fausch et al. 1990). Environmental integrity indices have been developed mainly for stream water systems and their metric components are in turn partial indices or indicators both of biotic and abiotic attributes (U.S. E.P.A. 1996).

The TRIX Index works like a multimetric index, moreover it offers the advantage of utilising, as components, environmental variables directly measured and routinely collected.

The main objective of the present paper is then to provide detailed information, with the aid of practical examples, on the data processing procedures necessary for the correct application of the TRIX Index: appropriate transformation of rough data; characterisation of TRIX statistical distributions; comparisons over different spatial and temporal trophic situations; discrimination limit between two contiguous means of TRIX; interrelationships between TRIX and its components and

\footnotetext{
(1) In fact, historic limnological thinking has for a long time applied trophic categorisation and respective denomination to lakes as a whole, not to distinctive package of water masses within lakes.
} 
between TRIX and other water quality-related variables.

The availability of a long-term data set related to coastal areas other than the NW Adriatic Sea, where TRIX was originally tested, allowed us to put in evidence quite different compositional features in terms of percent contribution of each original variable to the formulation of the Index. The weight of the TRIX two main aggregated components seems to be strictly related to the functional characteristics of "trophically different responding systems". In this respect, it was suddenly evident that the Adriatic coastal environment of EmiliaRomagna and the Tyrrhenian coastal environment of Tuscany, diverged above all because of the degree of nutrient utilisation, more relevant in the Adriatic, rather than in the Tyrrhenian waters. The "efficiency" concept, better defined in the following as a ratio between biotic and abiotic components, gives rise to a complex series of interpretative problems, but it however assumes a consistent meaning as "discriminating function" among coastal systems, like those under examination here.

\section{SOURCE OF THE ANALYTICAL DATA AND MEASUREMENTS}

The data-base "Si.Di.Mar" (Italian Ministry of Environment \& ICRAM - Central Institute of Marine Research, Rome - 2000) collects all the information provided by the monitoring activities along the coasts of the Italian peninsula, according to national legislation. Together with periodical measurements of physicalchemical parameters along the water column, surface values of chlorophyll- $a$, nutrient concentrations and phytoplankton biomass, are currently available. In particular, two time series of data were considered, related to the coastal belt of two Italian Regions and representative of the typical trophic conditions of the NW Adriatic Sea (Emilia-Romagna coast: highly productive waters) and of the Northern Tyrrhenian Sea (Tuscany coast: scarcely or moderately productive waters).

\subsection{Emilia Romagna data-base}

The data are referred to a three-years period, from July 1996 to June 1999. A number of 630 records were considered, with monthly samples (occasionally every two weeks), collected along 7 transects. Sampling stations per transect were located $500 \mathrm{~m}$ and $3000 \mathrm{~m}$ offshore. The entire reach of the monitored coastal area extends for about $90 \mathrm{~km}$, from transect n. 2 (Goro - Po River delta), to transect n. 19 (Cattolica) (Fig. 1).

\subsection{Tuscany data-base}

A number of 1179 records were taken into account, from May 1997 to April 1999, referred to 18 measure transects. Sampling frequencies were on average monthly and the sampling stations were located into the belt of $3000 \mathrm{~m}$ from the shore. The coastal reach monitored extends for at least $250 \mathrm{~km}$, from the Versilia coast, affected by the Arno and Serchio rivers loads (transects from n. 2 to n. 7), as far as to Ansedonia (transect n. 30). Other 4 transects are located in the oligotrophic waters around the Elba Island, the major island of the Tuscany archipelago (Fig. 1).

All the analytical data correspond to surface samples, collected during the diurnal hours.

\section{INDICES AND INDICATORS USED IN THE PRESENT WORK}

\subsection{Trophic Index TRIX ${ }^{(2)}$}

TRIX Index formulation is the following:

$$
T R I X=\left(\log _{10}[C h A \times a D \% O \times \operatorname{minN} \times T P]+k\right) / m
$$

Each of the four components represents a trophic state variable, to say:

a) factors that are direct expression of productivity:

- $\mathrm{ChA}=$ chlorophyll- $a$ concentration, as $\mu \mathrm{g} \mathrm{l}^{-1}$;

- $\quad \mathrm{aD} \% \mathrm{O}=$ Oxygen as absolute $\%$ deviation from saturation;

b) nutritional factors:

- $\operatorname{minN}=$ mineral nitrogen: dissolved inorganic nitrogen, $\mathrm{DIN}=\mathrm{N}\left(\right.$ as N-NO $\left.\mathrm{N}_{3}+\mathrm{N}-\mathrm{NO}_{2}+\mathrm{N}-\mathrm{NH}_{4}\right)$, as $\mu \mathrm{g}^{-1}$;

- $\quad \mathrm{TP}=$ total phosphorus, as $\mu \mathrm{g} \mathrm{l}^{-1}$.

The parameters $\mathrm{k}=1.5$ and $\mathrm{m}=12 / 10=1.2$, are scale coefficients, introduced to fix the lower limit value of the Index and the extension of the related Trophic Scale, from 0 to 10 TRIX units.

TRIX point values assign an immediate measurement to the trophic level of coastal waters. Referring to the Italian seas, values exceeding 6 TRIX units are typical of highly productive coastal waters, where the effects of Eutrophication determine frequent episodes of anoxia in bottom waters. Values lower than 4 TRIX units are instead associated to scarcely productive coastal waters, while values lower than 3 are usually found in the open sea. Because of the log-transformation of the four original variables, annual distributions of TRIX data over homogeneous coastal zones, are very close to normal kind and show a quite stable variance, with STD around 0.9.

\subsection{Efficiency Coefficient (Eff. Coeff.)}

The Efficiency Coefficient is defined as:

$$
\text { Eff. Coeff. }=\log _{10}([\mathrm{ChA} \times a \mathrm{D} \% \mathrm{O}] /[\operatorname{minN} \times \mathrm{TP}])
$$

to say as the log of the ratio between the two aggregated main components of TRIX.

Numerically, values are usually negative, ranging in our analyses from -4.48 (recorded in the Ionian Sea) to 0.45 (NW Adriatic Sea). We interpret the location of each case value within the total range of values as a

\footnotetext{
${ }^{(2)}$ For further and more detailed information on the TRIX Index, we refer to the original paper of Vollenweider et al. (1998).
} 


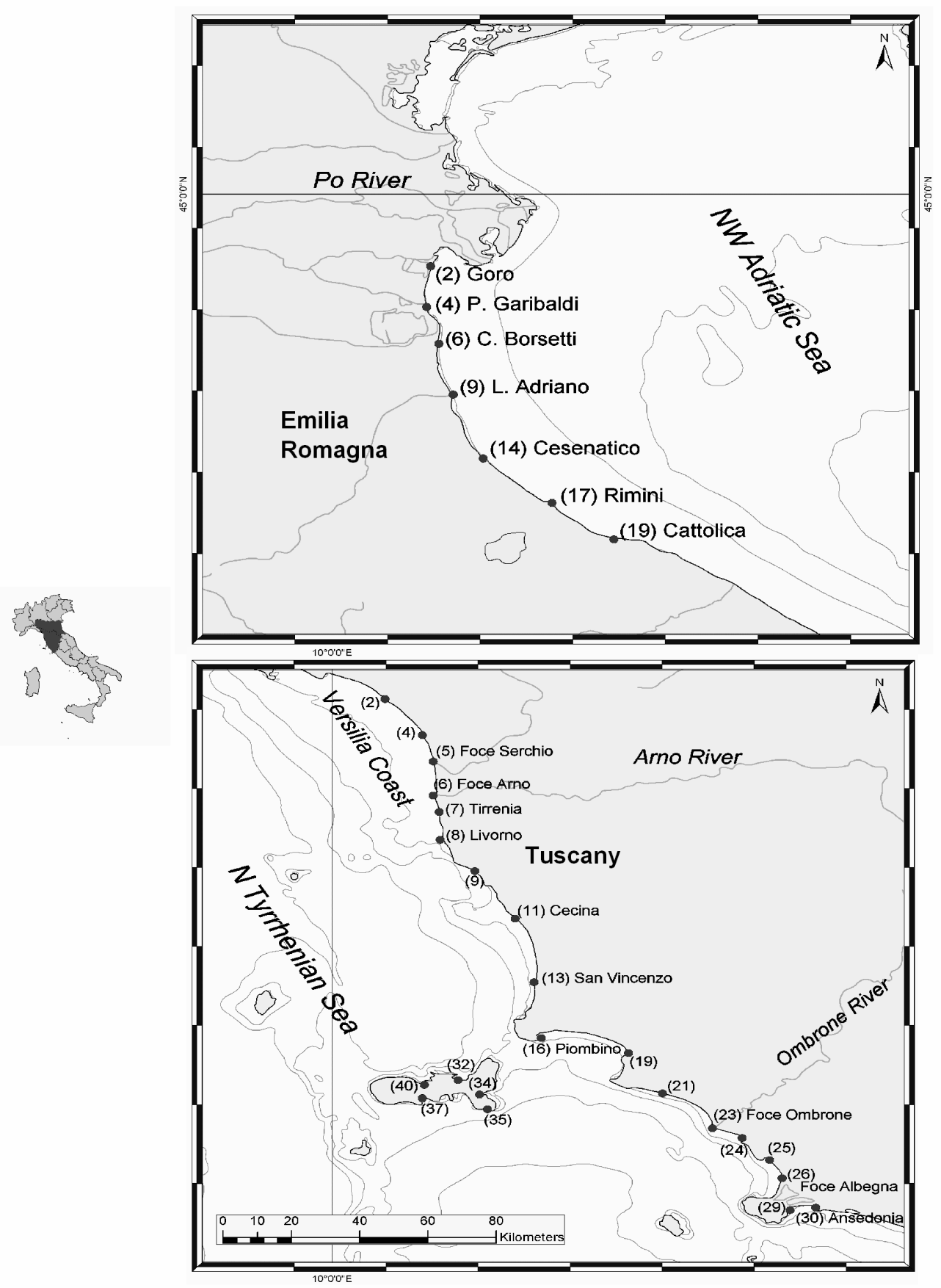

Fig. 1. Emilia Romagna and Tuscany coastal waters. Location of monitoring transects. (Italian Ministry of the Environment - SDM. \& ICRAM. National monitoring programme).

rough though realistic relative "measure of the degree of nutrient utilisation". Thus low values would indicate low, and vice versa, high values high nutrient utilisation. Alternatively, one may also think in terms of "actual" (with regard to each value as such), and "potential" productivity (with regard to its location relative to the highest value within the full value range); but this view is more questionable.

\subsection{Dilution factor}

The Dilution factor defines the freshwater content of the sea (Yentsch 1975). It is calculated as:

$$
F=\frac{S-S}{S}
$$

with $S=$ open sea salinity; $s=$ measured salinity. 
Tab. 1. Maximum of the Likelihood Functions $\left(L_{\max }\right)$ and corresponding $\lambda$ values. Adriatic Sea: Emilia Romagna coastal waters from Lido Adriano to Cesenatico; transects from 9 to 14. Sample size $=180$. Tyrrenian Sea: Tuscany coastal waters from Livorno to Ansedonia; transects from 8 to 30 . Sample size $=650$.

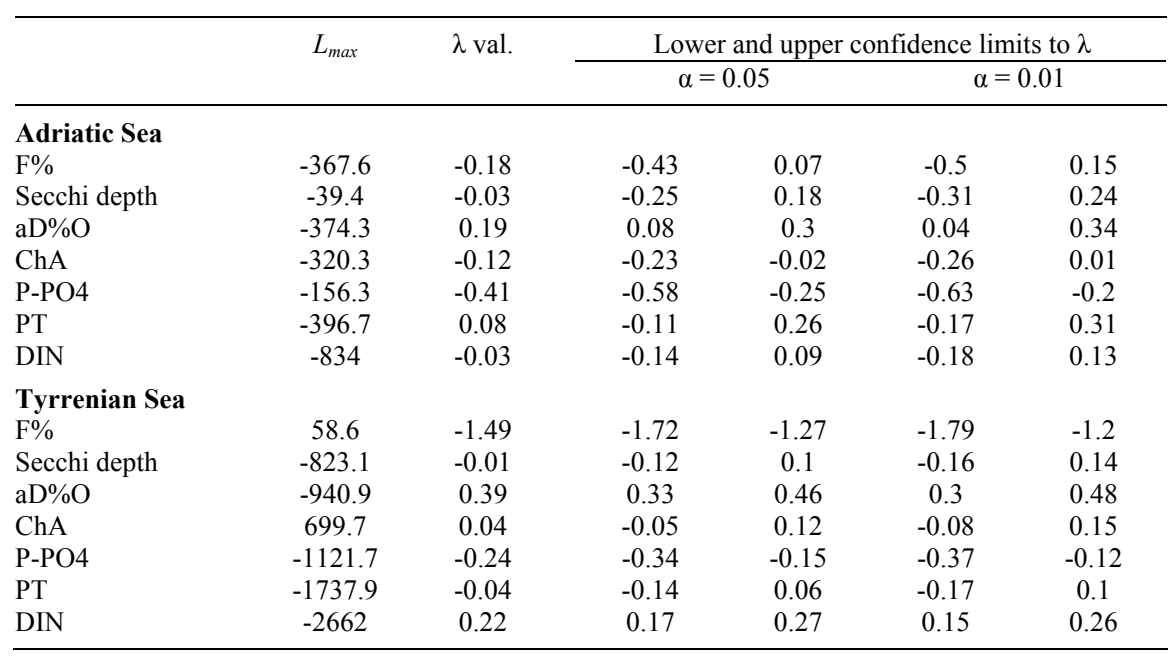

The value of this ratio in coastal waters changes from $0(S=s$ : open-sea situation) to $1(s=0$ : only freshwater). In estuarine areas or along coastal reaches affected by strong freshwater inputs, the expected concentration of a conservative substance entering the coastal zone, may be calculated as :

$$
C_{i}=C_{o} \times F
$$

starting from the initial concentration $C_{o}$ and from the salinity measurements, used as a tracer (Officer 1976). Referring to the Po River-Adriatic system, the expected surface concentration of total phosphorus was realistically evaluated as an empirical function of the progressive decrease of $F$ in the seawater (Giovanardi \& Tromellini 1992b).

\section{STATISTICAL PROPERTIES OF THE DATA}

\subsection{The transformation of the rough data}

When dealing with nutrients and chlorophyll data, a correct preliminary screening of the rough analytical data is still represented by the empirical method recommended by OECD (Vollenweider \& Kerekes, OECD, 1982): perform a base $10 \log$ transformation; remove the data exceeding the mean $\pm 2.5 \mathrm{STD}$; re-calculate the new average values and related STD. In practical terms, by following this procedure, only a few anomalous data are eliminated and the actual range of the resulting distributions covers a variation range from 2 to $3 \log _{10}$ units, in good agreement with a theoretical range of: mean $\pm 2.5 \mathrm{STD}$.

Referring to chlorophyll data distributions, the logtransformation allows to obtain normalisation and variance stabilisation, with a STD nearly constant, ranging from 0.3 to 0.4 (Giovanardi \& Tromellini 1992a). When working with data on biomass and dissolved nutrients, the log-transformation gives rise to several implications of biological nature. As an example, the base 2 logtransformation:

$$
\log _{2}(B)=\mu t
$$

represents the number of duplications necessary to obtain the biomass $B$ in the time $t$, with a constant growth rate $\mu$, starting from a single phytoplankton cell. Therefore logarithms, independently from the base, express in some way the "age" of the phytoplankton, even if one works with chlorophyll data, the main indicator of biomass. The processes of uptake and release of nutrients from and to the water column, are also of multiplicative kind (i.e. exponential), and they can be interpreted in a linear way by means of log-transformation (Innamorati \& Giovanardi 1992).

We have analysed each rough data distribution (to say the four TRIX components, plus other three variables not appearing in the TRIX formula, namely: P$\mathrm{PO}_{4}, \mathrm{~F} \%$ as percent of the Dilution factor and Secchi depth), by means of other empirical methods, which allow the general transformation function better approximating the original distributions to the normal law, to be determined.

According to the Box and Cox (1964) procedure (Sokal \& Rohlf 1995), the best function is represented by the following relationships:

$$
\begin{gathered}
y^{\prime}=\left(y^{\lambda}-1\right) / \lambda(\text { if } \lambda \neq 0) \\
y^{\prime}=\log (y)(\text { if } \lambda=0)
\end{gathered}
$$

where $y^{\prime}$ and $y$ represent the "transformed" data and the "untransformed" original data, respectively.

The requested $\lambda$ value is then the value maximising the Likelihood Function (see in detail Appendix A).

Table 1 shows the results obtained by applying the Box-Cox methodology to two sets of measurements, related to Adriatic and Tyrrhenian coastal waters. Assuming as a rule that the log-transformation works very 
well if the $\lambda$ confidence limits include the value zero, or if one of the limits is very close to zero, we can conclude that this kind of transformation of the rough data really proves appropriate for parameters referred to phytoplankton populations and to the environmental factors strongly influenced by organisms (Margalef 1965).

The goodness of log-transformation was also verified by means of the Kolmogorov-Smirnov test for single sample distributions (see e.g. Siegel \& Castellan 1992). As it is well-known, the Kolmogorov-Smirnov test requires that the distribution of the variable to be analysed is of a continuous kind. Accordingly, the test failed in the case of $\mathrm{P}_{-} \mathrm{PO}_{4}$ sample distributions related to the Emilia Romagna coastal waters, where $\mathrm{P}_{-} \mathrm{PO}_{4}$ concentration values are often extremely low. It must be stressed that the analytical methods currently in use present strong limitations of sensitivity for orthophosphates. If the $\mathrm{P}_{-} \mathrm{PO}_{4}$ values are lower than or close to the analytical detection limit, by convention these concentration values are usually put equal to the detection limit. In cases like that, a Normal Probability graph paper shows $\mathrm{P}_{-} \mathrm{PO}_{4}$ cumulative distributions to be of a continuous kind on the right side of the diagram (well detectable concentrations), but clearly discrete on the left side (lowest concentrations).

\subsection{Integrative feature of the TRIX Index}

The final combination of single components variability in an unique derived variable (see in detail Appendices $\mathrm{B}$ and $\mathrm{C}$ ), confer to the Index a distinctive integrative feature, immediately identifiable. In figure 2, pluriannual changes of the Index, recorded at station 314 (Cesenatico transect: Emilia Romagna coastal waters), are superimposed to the related components variations. By comparison, we observe that variation ranges of the single variables appear to be notably lowered and somewhat "softened" by the TRIX. Similar relationships also exist between TRIX Index and factors other than its components, as shown in figure 3 , where the temporal trends of TRIX and corresponding changes of Secchi depth, Dilution factor and Temperature, are compared. The diagram in figure 4 allows to analyse spatial variations along the entire Adriatic coastal belt, from Trieste (NE Adriatic Sea) to Manfredonia (Gargano Promontory-Southern Adriatic Sea). The data are referred to a monitoring campaign carried out by ICRAM during the Summer 1999 (Cicero et al. 2001).

By these diagrams we wish demonstrate that TRIX, as a synthetic index, works as an "integrating function": it summarises "more" than the sole variability expressed by the single components, it is well related to other important sources of variation that usually affect a coastal environment, both in time and space.

\subsection{Statistical procedures for a trophic characterisation by means of the TRIX Index}

In this section we propose suitable statistical procedures in order to study TRIX sample distributions and compare different trophic situations.

First, we consider the TRIX distributions related to the entire data sets of the two coastal zones of the Adriatic and Tyrrhenian seas. The graphical representation reported in figure 5, shows TRIX data points well aligned along the two trend-lines, that result well separated and characterised by an evident parallelism, since the respective STDs are almost equal. In the belt ranging between $1 \%$ and $99 \%$ of cumulative probability, these distributions cover as much as four TRIX units interval. Maximum point values, exceeding 6 TRIX units are more probable in the case of the Emilia Romagna coastal waters, where the risk associated with the Eutrophication phenomenon is quite elevated. Diagrams of this kind represent a useful diagnostic tool: they allow to plot together several TRIX distributions and help discriminate different trophic levels. In any case they reflect the great variety of trophic situations characterising coastal waters at a regional scale.

For management purposes, it is instead more important to identify critical areas with respect to nutrient loadings coming from rivers or local discharges, and to compare these coastal zones with reference areas, not directly affected by freshwater inputs. The first problem to be solved concerns therefore the pooling of the data, in order to aggregate TRIX values in statistically homogeneous samples, representative of local trophic conditions. Table 2 shows that the STDs related to the entire TRIX regional data sets, are quite higher than the corresponding pooled STDs among groups, calculated as follows:

$$
s_{p}=\sqrt{\frac{\sum N_{i} s_{i}^{2}}{\left(\sum N_{i}\right)-p}}
$$

where $N_{i}=$ number of data per group and $s_{i}=\mathrm{STD}$ of the $p$ groups. The arrangement of the TRIX data in a unique regional sample distribution becomes therefore very doubtful.

In general, in order to verify if the variances of two populations of data do not differ significantly, a onesided significance test is applied, based on the value of the statistic:

$$
F=s_{i}^{2} / s_{j}^{2}
$$

If $F>F\left(\alpha ; N_{i}-1, N_{j^{-}} 1\right)^{(3)}$, we have to reject the null hypothesis:

$$
H_{0}: s_{i}^{2}=s_{j}^{2}
$$

and to accept the alternative:

$$
H_{1}: s_{i}^{2}>s_{j}^{2}
$$

\footnotetext{
(3) The $F_{(1-\alpha)}$ critical value is to be found on the table of the upper percentage points of the $F$ distribution, usually reported on whatever statistics handbooks.
} 


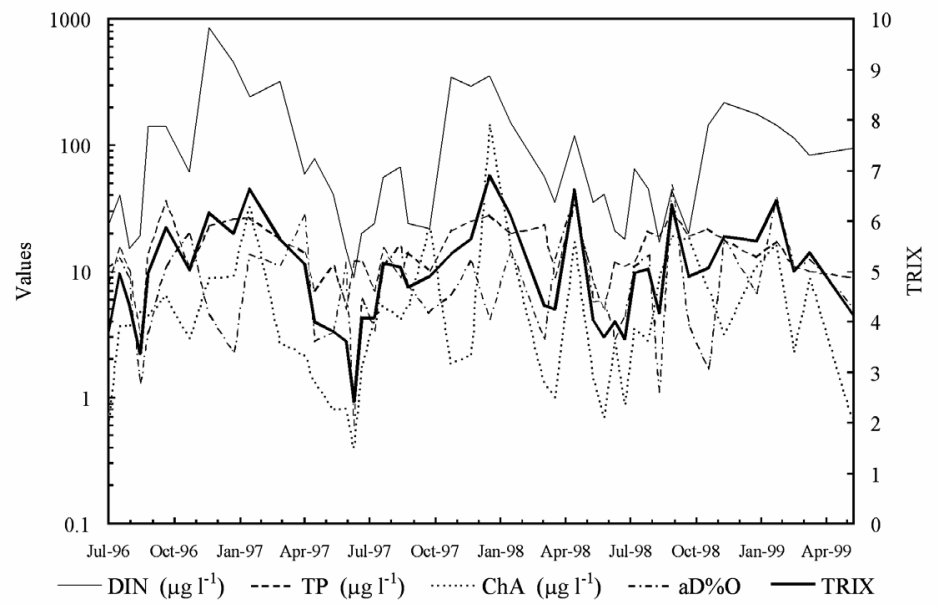

Fig. 2. Adriatic Sea - St. 314. Surface measurements - sampling station $3 \mathrm{~km}$ offshore. Multi-annual variations of TRIX and related original components.

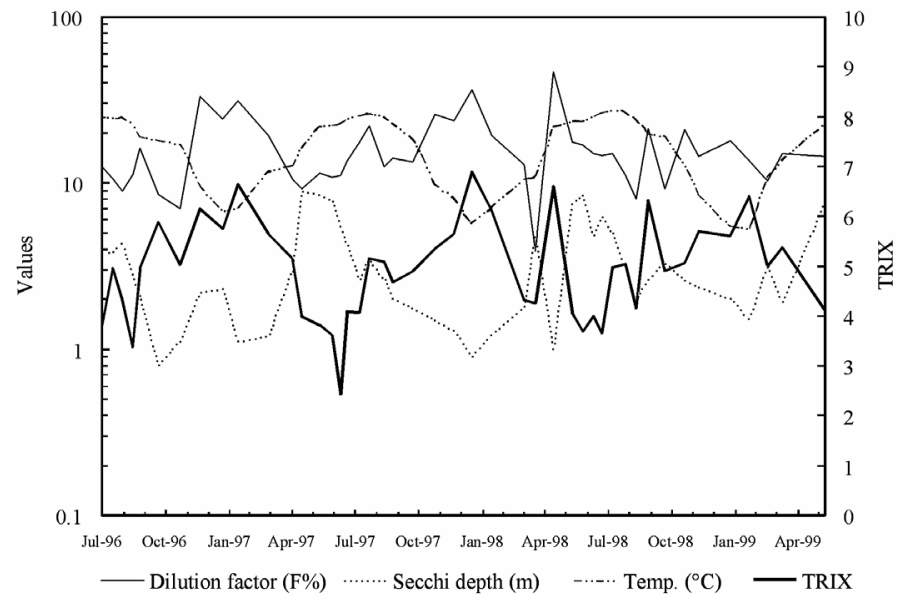

Fig. 3. Adriatic Sea - St. 314. Surface measurements - sampling station $3 \mathrm{~km}$ offshore. Multi-annual variations of TRIX and other parameters of interest.

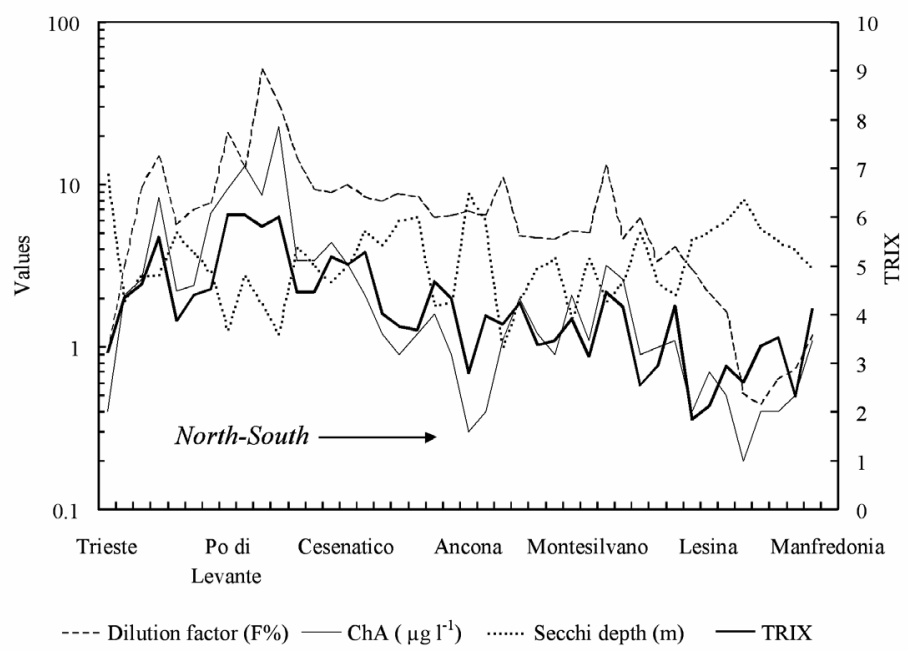

Fig. 4. Spatial variations of TRIX compared to other parameters of interest, along the Adriatic coast from Trieste to Manfredonia during July 1999; surface measurements, sampling stations $500 \mathrm{~m}$ offshore. Monitoring campaign carried out by ICRAM during summer 1999. 


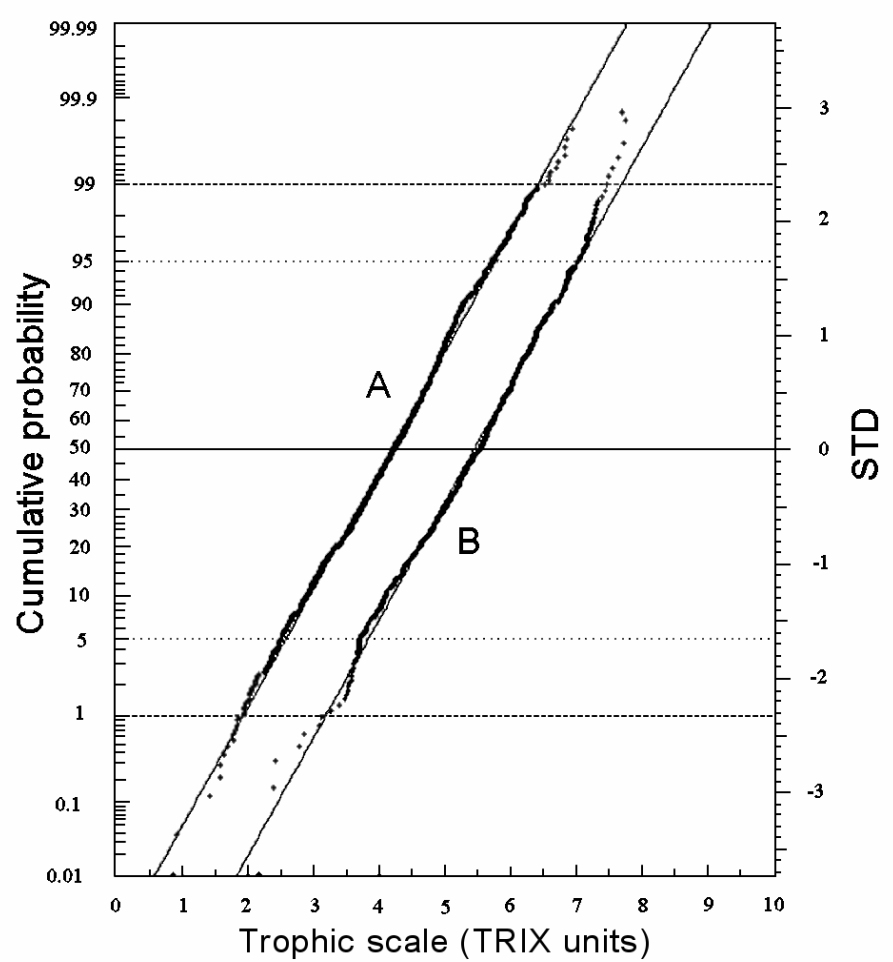

Fig. 5. Normal Probability graph paper for TRIX distributions: A) Northern Tyrrhenian Sea (Tuscany coast). B) NW Adriatic Sea (Emilia Romagna coast).

Tab. 2. Tyrrhenian and Adriatic coastal waters: statistical parameters of the TRIX distributions. (Whole Regional data-sets).

\begin{tabular}{lccccc}
\hline Sample size & $\begin{array}{c}\mathrm{N}^{\circ} \text { of transects } \\
\text { (Groups) }\end{array}$ & $\begin{array}{c}\text { General TRIX } \\
\text { means }\end{array}$ & $\begin{array}{c}\text { STD } \\
\text { (whole regional sample) }\end{array}$ & $\begin{array}{c}\text { Pooled STD } \\
\text { (among groups) }\end{array}$ \\
\hline Tuscany & 1179 & 23 & 4.17 & 0.964 & 0.870 \\
Emilia - Romagna & 630 & 7 & 5.44 & 0.967 & 0.881 \\
\hline
\end{tabular}

This procedure allowed distinct populations of TRIX data to be identified for each regional data set, according to the different sources of variation that a coastal system expresses on the trophic levels.

The second problem regards the comparison among group means, i.e. the assignment of a statistical significance to the difference between two means of TRIX, under the hypothesis that sample distributions belong to the same population, normally distributed. If the sample sizes is at least $\mathrm{N} \geq 50$, the hypothesis test to be adopted is based on the values assumed by the standard normal variable $z$. Say $d M$ the difference between two contiguous TRIX means, $d M$ will be significantly $\neq 0$, if the value of the statistic:

$$
z=\frac{d M}{\sigma_{\bar{x}_{i}-\bar{x}_{j}}}
$$

will exceed the corresponding critical value $z_{c}$, with a prefixed probability level $100(1-\alpha)$. In the above equation the difference $d M$ is scaled for the quantity:

$$
\sigma_{\bar{x}_{i}-\bar{x}_{j}}=\sqrt{\left(\sigma_{i}^{2} / N_{i}\right)+\left(\sigma_{j}^{2} / N_{j}\right)}
$$

representing the STD of the distribution of the means of the differences. In order to estimate $\sigma_{i}$ and $\sigma_{j}$, the corresponding sample STDs, $s_{i}$ and $s_{j}$, can be used.

By means of these hypothesis tests, the general TRIX distributions are now properly organised in subdistributions, as presented in the table 3. As for the Adriatic coastal area, two TRIX data populations characterised by their own variability, are well in evidence and correspond to: a) the Northern zone sampling stations, close to the Po River delta and homogeneous both for means and STDs, with the highest TRIX values; and b) the remaining regional coastal area, showing a progressive decrease in the trophic levels, along the NorthSouth direction. Tests on differences in TRIX means always gave significant results, except for the Cesenatico and Rimini statistical samples, which were therefore combined in an unique group. 
Tab. 3. Identification of homogeneous coastal sub-areas and parameters of the related TRIX distributions.

\begin{tabular}{|c|c|c|c|c|c|}
\hline \multirow[t]{2}{*}{ Transects } & \multirow[t]{2}{*}{ TRIX means } & \multicolumn{2}{|c|}{ STDs } & \multirow[t]{2}{*}{ Sample size } & \multirow{2}{*}{$\begin{array}{c}\text { \% of cases exceeding: } \\
\text { L = } 6 \text { TRIX Units } \\
\text { (Bad Trophic Status) }\end{array}$} \\
\hline & & on the whole & pooled & & \\
\hline \multicolumn{6}{|c|}{ Adriatic Sea: Emilia Romagna coastal waters } \\
\hline $2-4$ (from Goro to P. Garibaldi) & 5.940 & 0.731 & 0.731 & 180 & 47.6 \\
\hline 6 (Casal Borsetti) & 5.636 & 0.940 & & 90 & 35.2 \\
\hline 9 (Lido Adriano) & 5.392 & 0.885 & 0941 & 90 & 24.5 \\
\hline 14 - 17 (from Cesenatico to Rimini) & 5.181 & 0.951 & 0.941 & 180 & 20.6 \\
\hline 19 (Cattolica) & 4.803 & 0.977 & & 90 & 11.1 \\
\hline \multicolumn{6}{|c|}{ Tyrrhenian Sea: Tuscany coastal waters } \\
\hline $2-7$ (Versilia) & 4.825 & 1.047 & 0.939 & 258 & 13.4 \\
\hline 8 - 30 (from Livorno to Ansedonia) & 4.049 & 0.849 & 0.847 & 650 & 2.1 \\
\hline $32-40$ (Elba Island) & 3.831 & 0.846 & 0.855 & 271 & 0 \\
\hline
\end{tabular}

Concerning Tyrrhenian coastal waters, we distinguish two main areas: a) the Versilia coast, with relatively elevated trophic levels and high variability (STD on the whole sample $=1.047$ against a value of pooled STD $=0.939$ ), mainly due to outlying stations located just in front of the Arno River mouth; and b) the whole reach of coast from Livorno to Ansedonia (more than $200 \mathrm{~km}$ of littoral), that presents quite stable trophic levels with TRIX means around 4 units and a pooled $\mathrm{STD}=0.847$. A few exceptions are represented by onshore sampling stations affected by important urban and industrial settlements (e.g. Livorno, with TRIX mean $=$ $4.44 \pm \mathrm{STD}=0.695$ and Piombino, with TRIX mean $=$ $4.28 \pm \mathrm{STD}=0.755)$. The coastal belt around the Elba Island, provides instead the lowest TRIX values (TRIX mean always $<4$ units), in agreement with a judgement of "scarcely productive" coastal environment.

A complete information about the consequences of algal blooms connected to high trophic levels, in terms of both their frequency and intensity, cannot be provided by using TRIX means alone. A diagram with the frequency class distribution for TRIX data, as shown in figure 6 , assumes therefore an immediate and elevated informative value, especially in case of dissemination of the monitoring results to the public.

Due to the hypothesis of normality for single TRIX distributions, it is possible evaluate the probability of exceeding a prefixed TRIX point value, e.g. $L=6$, conventionally chosen as lower limit for a "bad" trophic status. By the experience acquired on the NW-Adriatic situations, one may also consider $L=5$, as a limit between "good" and "mediocre" trophic status.

The probability will be: $P=100(1-\alpha)$, when:

$$
z=\frac{L-\bar{x}_{i}}{s_{i}} \geq 0
$$

It will be $P=100 \alpha$, when:

$$
z=\frac{L-\bar{x}_{i}}{s_{i}}<0
$$

In the above formulas, $\bar{x}_{i}$ and $s_{i}$ are the mean and the STD of a given TRIX sample distribution and $\alpha$ represents the value of the normal cumulative distribution function for a given $|z|$ value. These probabilities are therefore associated with the "Eutrophication risk" and are reported in table 3 for each group, as a percent of cases exceeding $L=6$.

When designing a monitoring programme ${ }^{(4)}$, with the aim of comparing different trophic levels, the question that arises is how many samples are needed to obtain a reliable estimate of the difference between two contiguous TRIX means. Obviously this Discrimination Limit (i.e., the resolution power of a test on the differences), depends on the sample size; here, with sample sizes usually $\geq 50$, the critical value of this difference was evaluated as:

$$
\text { Discriminant limit }= \pm z_{c} \cdot \sigma_{\bar{x}_{i}-\bar{x}_{j}}
$$

This limit resulted very low, within the range between $1 / 10$ and 2/10 units of TRIX.

In general, it is possible evaluate a priori the minimum level of resolution requested. With small samples $(\mathrm{N}<50)$, for two TRIX distributions, randomly extracted from the same normal population, the following condition is worth:

$$
d M=s_{p} \cdot t_{\left(\alpha / 2 ; N_{1}+N_{2}-2\right)} \cdot \sqrt{\left(1 / N_{1}+1 / N_{2}\right)} \neq 0
$$

In the particular case $\mathrm{N}_{1}=\mathrm{N}_{2}=\mathrm{N}$, the degrees of freedom for the variable $t$ become $(2 N-2)$ and the term under root becomes $(2 / N)$. Assuming conventionally a pooled STD $s_{p}=0.9$, at an opportune significance level $\alpha / 2=0.025$ (with $P=95 \%)^{(5)}$, the following results are obtained:

$$
\begin{array}{lllll}
\text { 1) With: } & N=12 & t=2.074 & \sqrt{ }(2 / 12)=0.408 & d M>|0.76| \\
\text { 2) } & N=52 & t=1.983 & \sqrt{ }(2 / 52)=0.196 & d M>|0.35| \\
3) & N=100 & t=1.972 & \sqrt{ }(2 / 100)=0.141 & d M>|0.25|
\end{array}
$$

Nevertheless, with an yearly monitoring programme

\footnotetext{
(4) About monitoring programmes design, strategies and criteria, see also Ward et al. 1990.

${ }^{(5)}$ In that case, we apply a two-sided test. The critical value $t_{(I-\alpha / 2)}$ is to be found on the table of the upper percentage points of the $t$ distribution.
} 


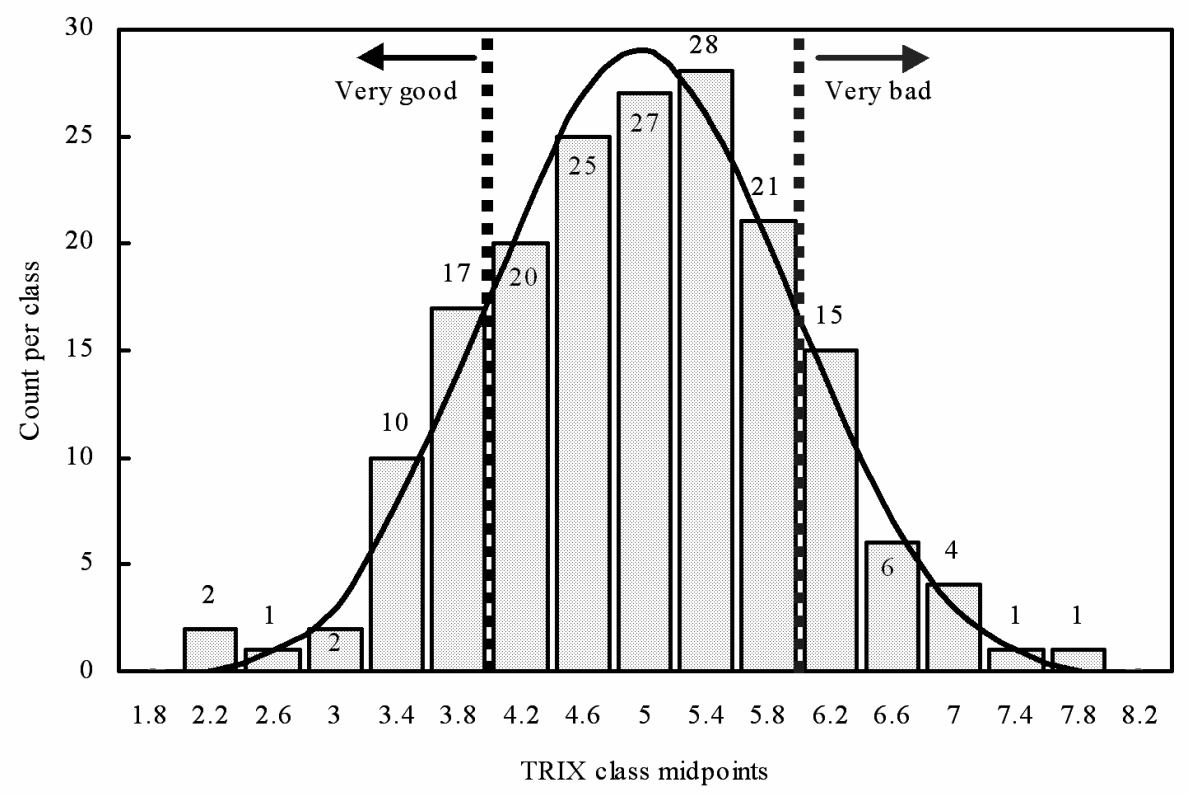

Fig. 6. Adriatic coastal waters. Frequency class distribution for TRIX data. Sampling stations 500 and $3000 \mathrm{~m}$ offshore, from Cesenatico to Cattolica (Transects 14-17-19).

and a monthly sampling frequency (case 1), we would reach a discrimination level between two measurement stations equal to 0.76 TRIX units, not indeed favourable. With a weekly sampling frequency (case 2), the limit descends to 0.35 TRIX units, a value surely more acceptable. Finally (case 3), with 100 data per year per station, a value of 0.25 TRIX units is obtained. The monitoring programmes presently carried out in Italy foreseen at least one or two monthly samples per station. Moreover, two or more sampling points can be aggregated in statistically homogeneous groups following the above mentioned rules, in such a way that discrimination limits $\leq 1 / 4$ of TRIX units can be easily overtaken, allowing spatial and temporal comparisons to be more accurate and reliable.

\section{SYSTEMS BEHAVIOUR AND FUNCTIONAL RELATIONSHIPS BETWEEN TRIX AND RELATED VARIABLES OF TROPHIC STATE}

An inspection of table 3, as regards TRIX mean values, shows that NW-Adriatic coastal waters result in general more productive than the Tyrrhenian ones. The nature of this difference in trophic levels can be better explained by analysing annual changes of some important attributes of the systems. Figure 7 reports monthly variations of nutrients, chlorophyll- $a$ and N/P ratio, as geometric means. The data are referred to the Cesenatico-Rimini transects (NWAdriatic Sea: TRIX mean $=5.181$ ) and to the Versilia coast transects (Tyrrhenian Sea: TRIX mean $=4.825)$; in this case the two coastal zones chosen are apparently characterised by similar trophic levels, differing by only 0.36 TRIX units.

Taking into consideration the N/P ratios, Tyrrhenian coastal waters present a nitrogen-limitation condition for a great part of the year (N/P in weight $=c a 5$, as average from May to September), never exceeding a value of $\mathrm{N} / \mathrm{P}=13$, not even during the winter months. In the Adriatic Sea, orthophosphate concentrations are often very close to the analytical detection limit, with an yearly mean value of about $3 \mu \mathrm{g} \mathrm{l}^{-1}$, without evident seasonal peaks. Accordingly, the Adriatic system would result always phosphorus-limited, never descending below a minimum limit of $\mathrm{N} / \mathrm{P}=14$ in the summertime, against a maximum value of $\mathrm{N} / \mathrm{P}=87$ in January.

Nevertheless, concerning nitrogen and phosphorus availability, limitation of primary production in the Adriatic occurs neither in winter-spring, when diatoms blooms take place, nor in autumn: the concentration of chlorophyll- $a$ is very high, exceeding values of $20 \mu \mathrm{g}^{-1}$ in January and February, with another peak in October of about $10 \mu \mathrm{g} \mathrm{l}^{-1}$. When algal growth slows down (ChA $<2 \mu \mathrm{g}^{-1}$ in June-July), the lowest ChA concentrations coincide with the minimum values of DIN, probably due to the very poor freshwater inputs coming from the Po River, because of the dry weather. We interpret this behaviour as a direct response of the Adriatic coastal system to the scarce availability, not only of phosphorus, but also of nitrogen, in such a way that, during summertime, both the nutrients seem to be limiting.

As for the Tyrrhenian situation, chlorophyll- $a$ values are several times lower than the Adriatic counterpart: ChA concentrations vary from a minimum of $0.5 \mu \mathrm{g}^{-1}$ in August and September, to as far as about $2 \mu \mathrm{g} \mathrm{l}^{-1}$ recorded in April and June, without peaks of some relevance, especially if compared with the range of the Emilia Romagna seasonal variations. Changes in $\mathrm{P}_{-} \mathrm{PO}_{4}$ monthly values are quite stable, but the average concentrations of this immediately available form of phos- 
a)

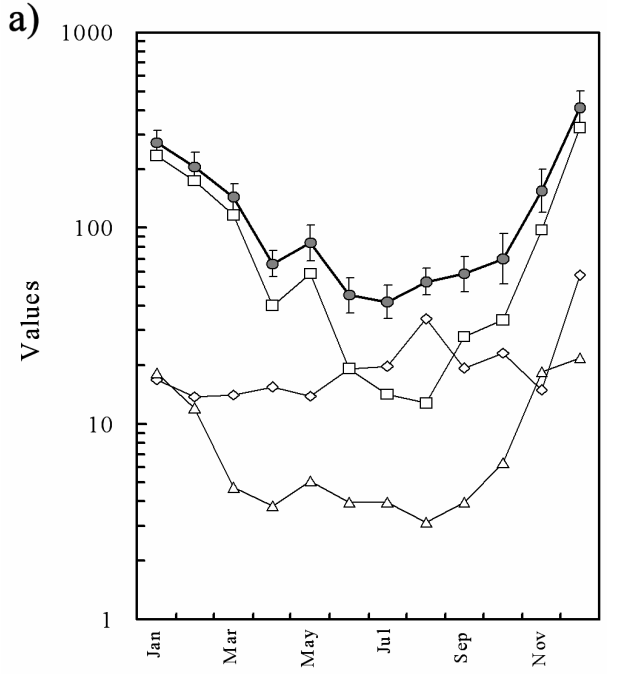

c)

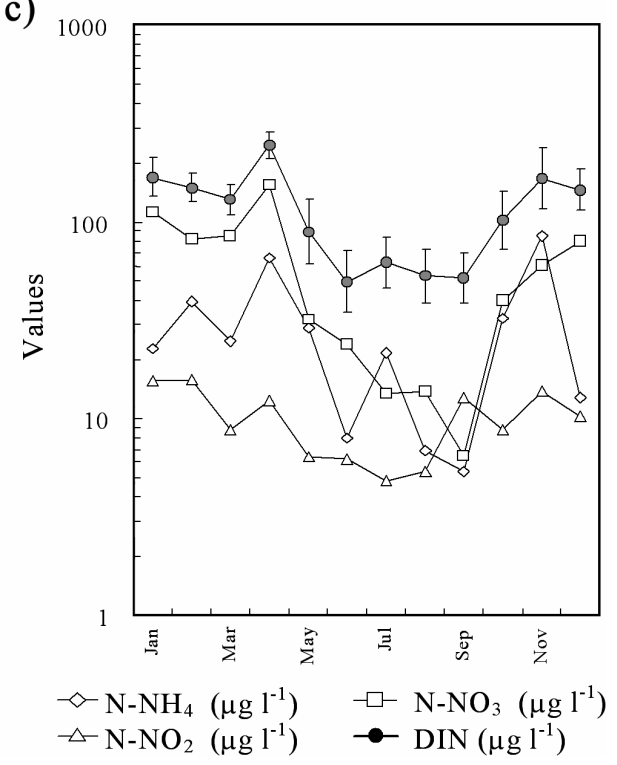

b)

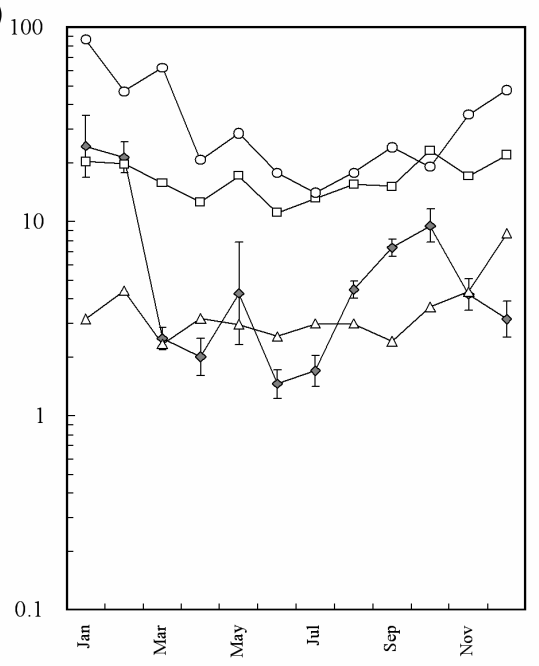

d)

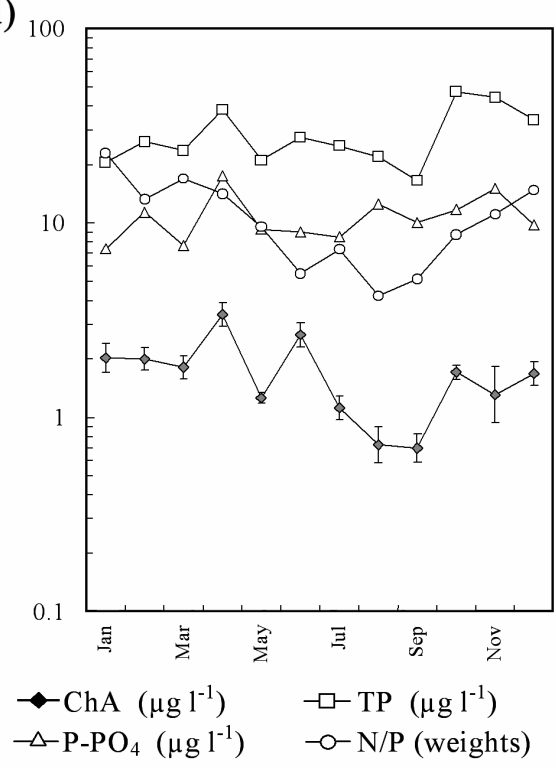

Fig. 7. Monthly variations of some important system parameters (geometric averages). a) and b): Emilia Romagna coastal waters, Cesenatico and Rimini transects combined. c) and d): Tuscany coastal waters, Versilia coast.

phorus are around $10 \mu \mathrm{g}^{-1}$, at least 3 times higher than the corresponding Adriatic $\mathrm{P}_{-} \mathrm{PO}_{4}$ means. In spite of a continuous nutrients availability round the year, the response in terms of biomass production results notably reduced, according to a judgement of oligotrophic environment, often expressed for the Tyrrhenian surface waters (Innamorati 1989).

These trophic peculiarities determine different compositional features on the TRIX annual means, in terms both of contribution in weight and percentage of total variability explained by the original components, as reported in table 4. Referring to the Adriatic TRIX data, the weight of the aggregated component "direct expression of productivity", i.e. $\log (\mathrm{ChA} \times \mathrm{aD} \% \mathrm{O})$, reaches a maximum of $41 \%$ in February (as a monthly mean, with point values exceeding $50 \%$ ). Conversely, in the Tuscany TRIX data, the abiotic component $\log (\mathrm{DIN} \times \mathrm{TP})$ contributes yearly with more than $80 \%$ in the composition of the Index, exceeding a maximum of $90 \%$ in August.

Tab. 4. Contribution of the main aggregated components to the TRIX formulation and to the related variability. Cfr. Appendix C - equations (18) \& (20).

\begin{tabular}{|c|c|c|}
\hline & $\begin{array}{c}\text { Weights } \\
\%\end{array}$ & $\begin{array}{c}\text { s Overall } \\
\text { Variability } \\
\%\end{array}$ \\
\hline \multicolumn{3}{|c|}{ Cesenatico-Rimini transects (NW Adriatic Sea) } \\
\hline $\log (\mathrm{ChA} \times \mathrm{aD} \% \mathrm{O})$ & 33.4 & 41.5 \\
\hline $\log (\mathrm{DIN} \times \mathrm{PT})$ & 66.6 & 28.8 \\
\hline Covariances & - & 29.7 \\
\hline \multicolumn{3}{|c|}{ Versilia coast (Tyrrhenian Sea) } \\
\hline $\log (\mathrm{ChA} \times \mathrm{aD} \% \mathrm{O})$ & 19.2 & 22.9 \\
\hline $\log (\mathrm{DIN} \times \mathrm{PT})$ & 80.8 & 49.3 \\
\hline Covariances & - & 27.7 \\
\hline
\end{tabular}


As for the overall TRIX variability, two opposite situations arise, with a remarkable percentage contribution of $\log (\mathrm{ChA} \times \mathrm{aD} \% \mathrm{O})$ in the Adriatic TRIX data and, vice versa, a distinct prevalence of the other aggregate component $\log (\mathrm{DIN} \times \mathrm{TP})$, in controlling the actual variations of the Tyrrhenian TRIX data. We conclude that TRIX alternatively reflects two specific trophic regimes: the Adriatic, where it seems to express the actual productivity, to say what the system "really does", and the Tyrrhenian, where it appears instead to be dominated by the nutritional factors component, to say as an expression of what the system "potentially could do".

With the diagrams presented in figure 8 , this matter is further deepened and better defined.

Variations of TRIX mean values per sampling station, as a function of the geometric averages of the four components of the Index, plus Secchi depth, F\%, N/P and $\mathrm{P}_{-} \mathrm{PO}_{4}$, are reported ${ }^{(6)}$. Regression analysis was performed on the whole 59 couples of data, 14 sampling stations for Emilia Romagna and 45 for Tuscany coastal waters. The use of the geometric means instead of ungrouped single data points, is allowed because of the acquired normalisation of every single distribution, by means of the $\log _{10}$-transformation (see section 4.1.). By experience, the ungrouped value statistics may result in lower correlation, while the group statistics can provide high level of correlation (Vollenweider et al. 1992). By testing single regional data sets, clear functional relationships come out between TRIX means and each of the main trophic state variables. By combining the two regional samples, data points of several variables are well aligned, close to the common interpolation curve (i.e. TRIX-ChA, - $\mathrm{aD} \% \mathrm{O}$, -DIN, -F\%, -Secchi d., -N/P); the correlation remains very high, in certain cases even increases.

This is not true for the connections TRIX-TP and TRIX-(P-PO $\left.{ }_{4}\right)$; a manifest discrepancy exists in phosphorus data from Emilia-Romagna and Tuscany, that cannot simply be ignored. If we consider the orthophosphate data without treating them separately, an inverse dependency TRIX-(P-PO $\left.\mathrm{P}_{4}\right)$, although not very significant, would result. Evident disparities are also observed by plotting $\mathrm{P}_{-} \mathrm{PO}_{4}$ data against the corresponding TP forms (Fig. 9a). The averages of the ratio $\mathrm{P}_{-} \mathrm{PO}_{4} / \mathrm{TP}$ are worth 0.17 and 0.40 , for Emilia Romagna and Tuscany respectively. These results indicate that, in relative terms, more than the $80 \%$ of the Adriatic TP is invested in the particulate fraction (plus the dissolved-organic), much less in the Tyrrhenian.

\section{DISCUSSION}

The peculiar behaviour of phosphorus, so diverse in the two coastal environments examined, gives support to the thesis that two different dynamics exist with re- spect to nutritional factors, and more in general to the resources available to the system, which could have not been appreciated by using TRIX alone. In this context, the Efficiency Coefficient, as defined in section 3.2., plays therefore the role of supplementary index, in terms of a "discriminating tool". In fact, by plotting Eff. Coeff. against the corresponding TRIX values, as represented in figure $9 b$, two distinct clouds of points are identified, depending on the Adriatic and Tyrrhenian trophic regimes, respectively; the relative location of the two systems in the diagram allows to discriminate between their related High and Low Efficiency.

A slightly different approach to the concept of efficiency was also developed in an already mentioned paper (Innamorati \& Giovanardi 1998). In studying normal bi-variate distributions of chlorophyll-dissolved nutrients ratios, with the aim of representing seasonal fluctuations of the main system parameters, a general reference diagram was set up, where different coastal areas could be located, depending on their average N/P molar ratio and on the value of the ratio $C h A /{\sqrt{\left(D I N \cdot P O_{4}\right)}}^{(7)}$, the latter being worth as a coarse estimate of the degree of utilisation of nutrients and having substantially the same meaning of Eff. Coeff.

Annual variations of $\mathrm{ChA} /\left(\mathrm{PO}_{4}\right)$ and $\mathrm{ChA} / \mathrm{DIN}$ monthly averages for two Tyrrhenian subgroups and two Adriatic subgroups, are analysed in a diagram of this kind, as shown in figure 10.

The distinctive feature of this diagram (see in detail Appendix D) with respect to that presented in figure 9b, resides in the fact that the efficiency has to be read on the oblique coordinate: the $\mathrm{ChA} / \sqrt{\left(\mathrm{DIN} \cdot \mathrm{PO}_{4}\right)}$ ratios are constant along the $-45^{\circ}$ lines and increase from the left to the right, vice versa the $\mathrm{N} / \mathrm{P}$ ratios are constant along the $45^{\circ}$ lines, and increase from the right to the left. We are now able to observe the oscillations of the systems, month by month, around a gravity centre, represented by the annual mean values assumed by the related ratios.

According to the amplitude of the seasonal oscillations, the Adriatic coastal area is characterised by a higher variability. The further subdivision into subgroups, which take into account possible effects of the two main sources of loadings and freshwater inputs, i.e. the Po River (from Goro to Casalborsetti sampling stations), and the Arno River (Versilia coast sampling stations), does not modify substantially the general behaviour of the two main systems, that maintain well distinctly their own trophic peculiarities: close to the Redfield ratio the Tyrrhenian sub-groups and denoting a strong P-limitation the Adriatic. Numerically, the annual mean values of the efficiency parameter result at least ten times higher in the Adriatic subgroups (5.7 and 6.8 against values of 0.5 and 0.8 in Tyrrhenian sub-systems).

\footnotetext{
(6) TRIX is formerly a logarithmic function by itself. The interpolation curves adopted are therefore of the kind: TRIX $=\mathrm{a}+$ $\mathrm{b} \times \log$ (Factor), to which is referred too the Determination coeff. reported in the diagrams.

${ }^{(7)}[\mathrm{ChA}]$ as $\mu \mathrm{g} \mathrm{l}^{-1},\left[\mathrm{PO}_{4}\right]$ and $[\mathrm{DIN}]$ as $\mu \mathrm{mol}^{-1}$.
} 

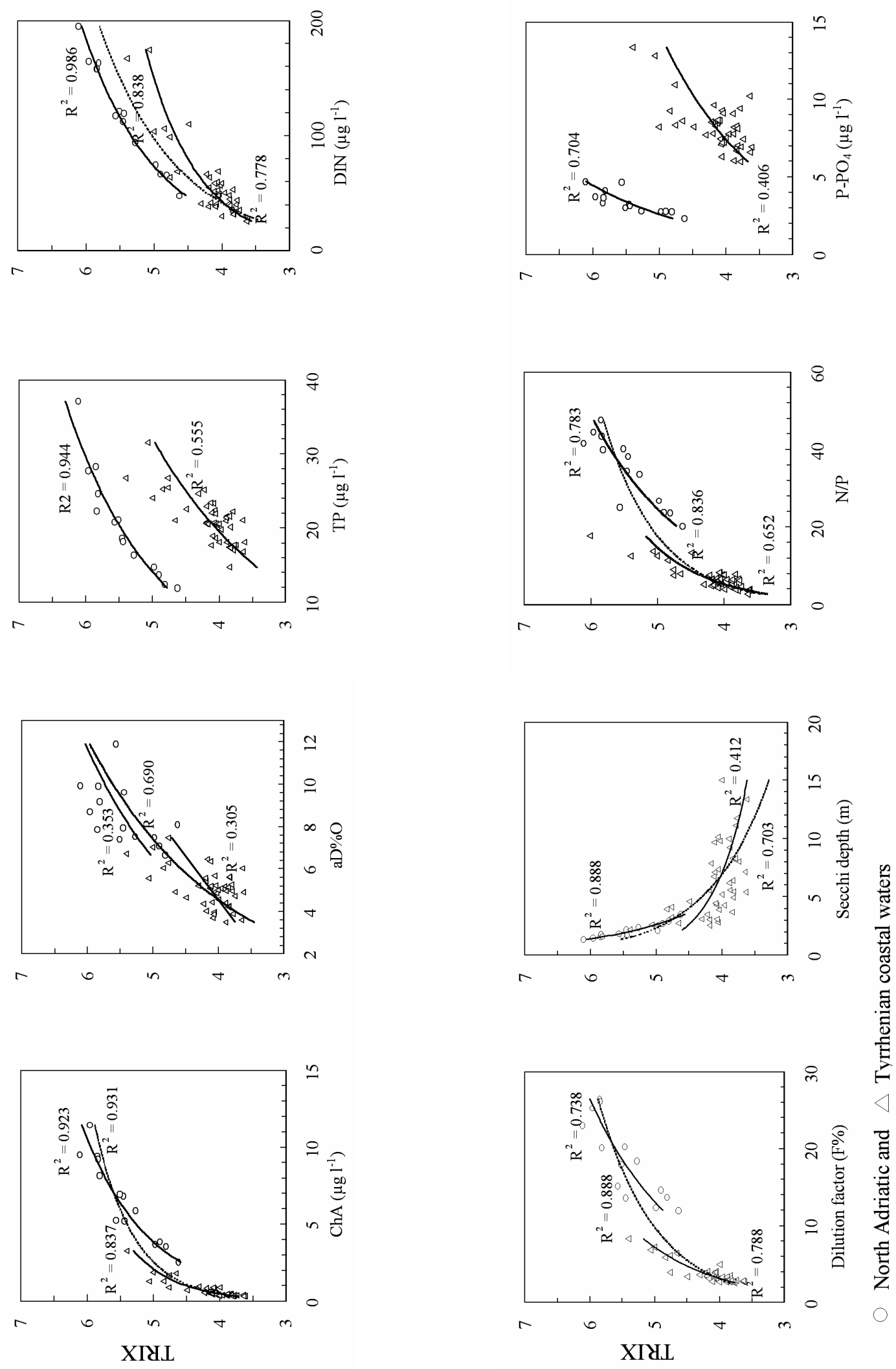

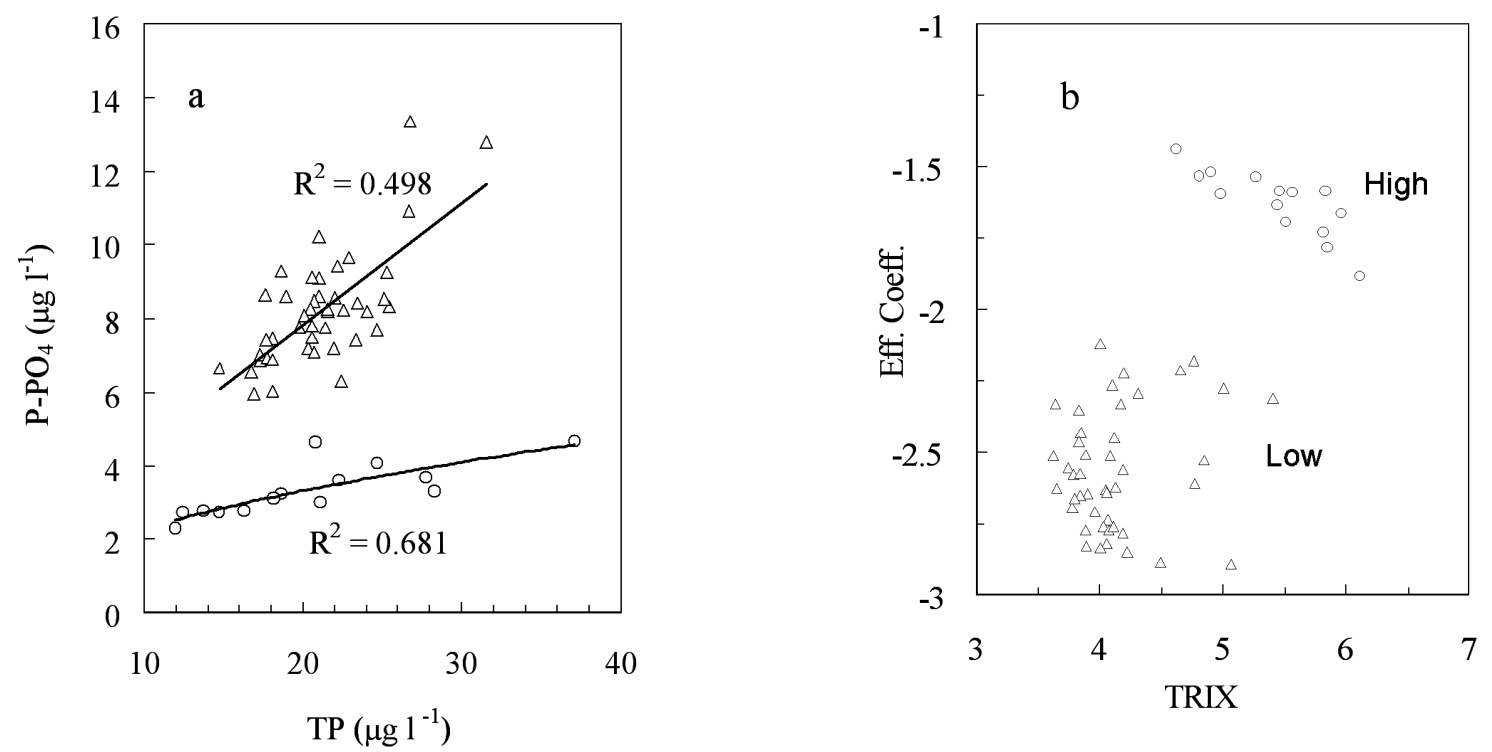

Fig. 9. Emilia Romagna (circles) and Tuscany (triangles) data combined. a) Phosphorus-orthophosphate variations against corresponding total phosphorus concentrations (as geometric means per sampling station). b) Nutrient utilisation: Efficiency Coefficient vs TRIX means, per sampling station.

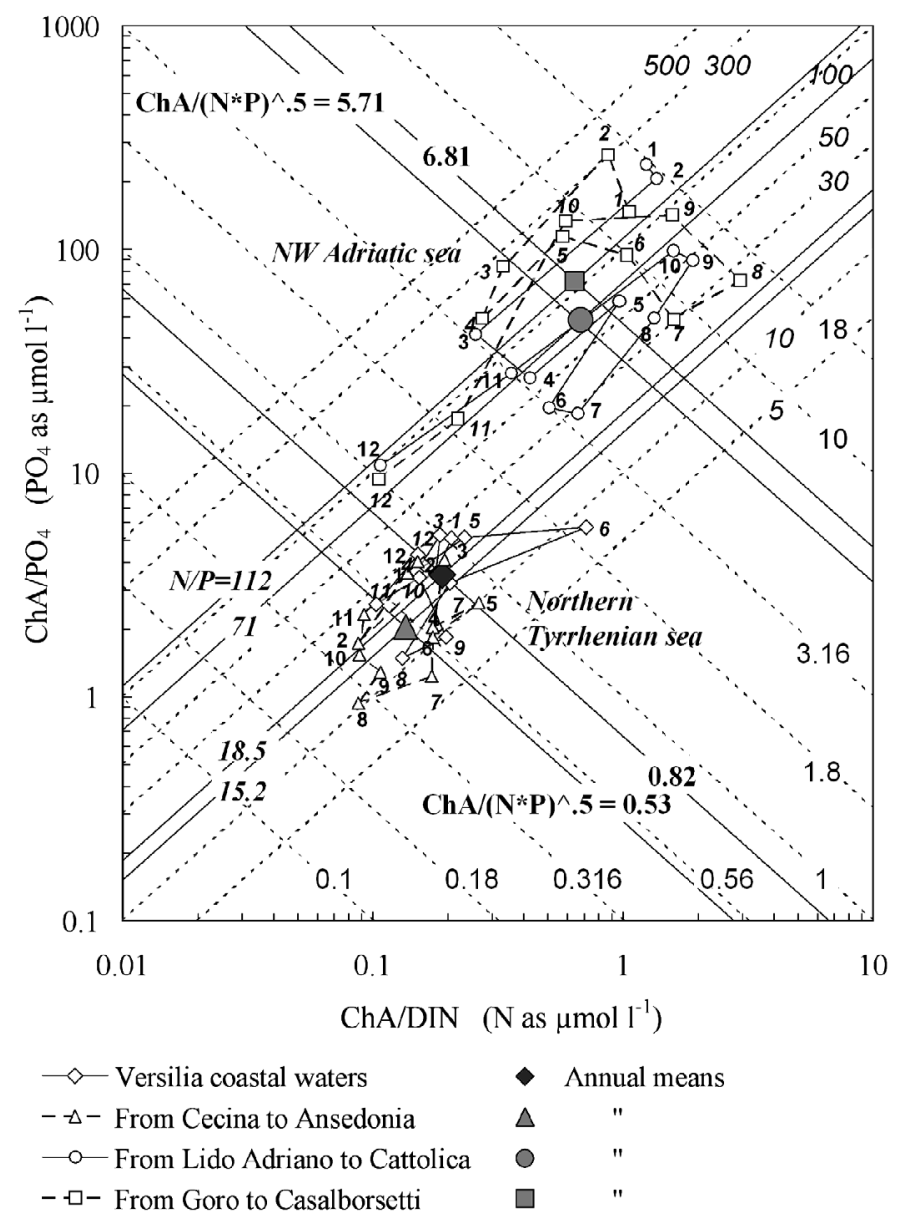

Fig. 10. Reference Diagram for Coastal Systems Trophic State. (N/P ratios are constant along the dotted $45^{\circ}$ lines, vice versa $\mathrm{ChA} / \sqrt{\left(\mathrm{DIN} \cdot \mathrm{PO}_{4}\right)}$ ratios are constant along the dotted $-45^{\circ}$ lines. Corresponding values of the related annual means are represented by solid straight lines. 
a)

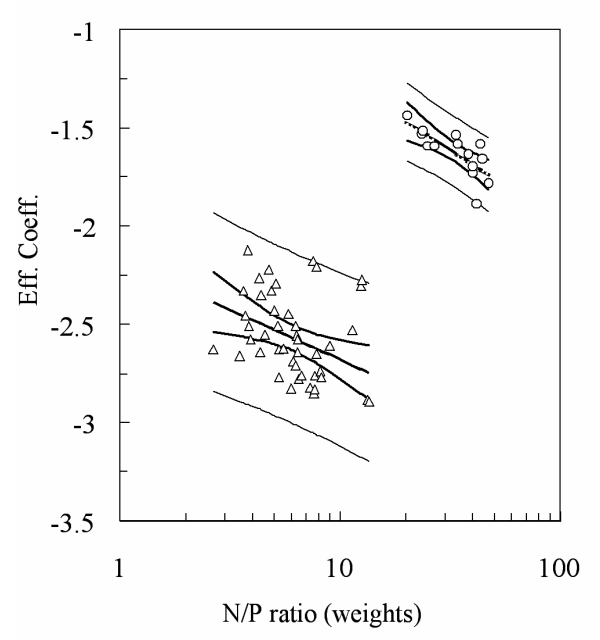

b)

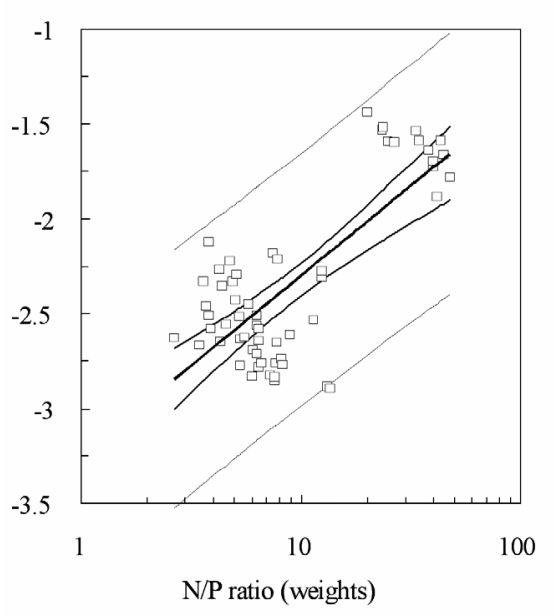

Emilia Romagna $\triangle$ Tuscany

Fig. 11. Differences in Utilisation Efficiency as a function of N/P ratios (geometric averages per sampling station).

In conclusion, by juxtaposing different coastal systems in such a reference diagram, marine environments may be analysed and identified as follows: 1) in absolute terms, on the basis of their "actual productivity", i.e. the efficiency numerical values as such, and the corresponding annual changes, or 2) in relative terms, on the basis of the location of a single system data points in comparison with others. Consequently, we propose to consider the distance between two centroids, identified by the related $C h A / \sqrt{\left(D I N \cdot P O_{4}\right)}$ annual mean values, as a measure of the divergence in the degree of utilisation of the nutritional factors. In an analogous way, Eff. Coeff. plotted against the corresponding TRIX values, would assume an equivalent discriminating function.

\section{CONCLUSIONS}

Referring to the tropho-dynamic relationships as represented in figure 10, the Tyrrhenian system seems to be limited by factors other than nutrients in determining the "actual" productivity, to say that nutrients are not utilised to their maximum potential. Now the arising question is what are the causal factors of the evident "divergence" between the two coastal systems. To impute the difference in nutrients utilisation only to the $\mathrm{N} / \mathrm{P}$ ratio, i.e. to nutritional conditions, appears to be not wholly convincing. Perplexities derive mainly from analysing the diagrams reported in figure 11. By plotting the N/P ratios from Emilia Romagna and Tuscany data against the related Eff. Coeff. and treating the two groups separately, we obtain inverse relationships, with interpolation lines nearly parallel (Fig. 11a). We have clearly the sensation that the groups of data points do not pertain to the same continuum. In fact, the alternative would be to accept the hypothesis of a direct proportionality. By examining figure $11 \mathrm{~b}$, this hypothesis appears to be very doubtful: we cannot assert, as a general rule, that high (or low) levels of efficiency correspond to high (or low) N/P ratios and vice versa.

By discarding the latter hypothesis, as a logical consequence, we have to recognize that both the expressions

$$
\begin{gathered}
C h A / \sqrt{\left(\mathrm{DIN} \cdot \mathrm{PO}_{4}\right)} \text { and } \\
\log _{10}([\mathrm{ChA} \times a D \% O] /[\operatorname{minN} \times T P])
\end{gathered}
$$

as response-variables, characterise a framework of functional relationships where, in addition to the factors used for their definition, the effects of other factors that co-determine dynamics and behaviour of the systems, are integrated.

Among the possible factors, the notable difference in Secchi transparency between Emilia Romagna and Tuscany data (as reported in figure 8 , in relation to TRIX values), should be taken into account. Secchi depth, as a water clarity indicator, is another important integrator of trophic characteristics, unfortunately today often considered as a too simplistic measurement ${ }^{(8)}$. In any case it is necessary to define in a better way the photic regime of coastal environments. This would be possible if, in addition to the water transparency, coastal zones under comparison were also distinguished in their average conditions of vertical stability, that is in the dynamics of the surface layers (cycles of stratification and vertical

\footnotetext{
${ }^{(8)}$ It is worth to remark that "this simple and subjective data-gathering procedure .... can be converted into quantitative expressions for the depth rate of decay of natural light in natural waters" (Bukata et al. 1995).
} 
mixing). By experience the thickness of the mixing layer in the Adriatic is thinner than in the Tyrrhenian surface waters. Accordingly, diverse photic regimes could take place, in relation to the amount of photosynthetically active radiation available along the water column. Moreover, the presence of strong vertical density gradients, could determine greater variance in nutrient distributions and this clearly reflects different trophic situations, related to the availability of the nutrient reserves for the phytoplankton growth (Harris 1986).

If the connection between photic regime induced by water column stability-instability, and effectiveness of utilisation is a valid hypothesis, we have to re-consider our approach and to think in terms of scales of the phenomena (Harris 1986; Platt 1981a; Denman \& Gargett 1983). Time-scales and length-scales of physical and physiological phenomena characterizing coastal water bodies, and more generally the upper ocean waters, strongly affect tropho-dynamic processes, as largely discussed in the above cited literature. The absence of direct data and measurements for physical transport, eddy diffusion, horizontal and vertical mixing, light attenuation, euphotic and mixing depths ratio, etc., se- verely limits our understanding of the mechanisms by which biological changes are produced. However, effective comparisons among coastal environments can be only performed on a quantitative basis. There is surely a need for more extensive observations of this kind in our routine monitoring activities.

Concepts like ecological and chemical "status", as recalled at the beginning of this paper, are of course static expressions specifically introduced by EC legislation in order to fix, "on average", the quality characteristics of a water body. TRIX Index, as a numeric expression which provides a direct measure of trophic levels, is fully consistent with this approach. On the other hand, in analysing monitoring results, we have to consider that "a static representation of a dynamic system is of but limited utility" (Platt 1981b). With this in mind, we have tentatively indicated new perspectives of research in interpreting environmental data and in designing future monitoring programmes, being aware that the main objective to be gained is always the "sufficient scientific knowledge" of the problems, and trying, after all, to put a little order in a matter so complex, according to the Shakespeare saying "there is system in his (its) madness". 


\section{APPENDIX A}

\section{The Box-Cox transformation (Sokal \& Rohlf 1995)}

Although from a point of view strictly statistical there are not a priori reasons to adopt log-transformation as a general rule, rough data distributions of different parameters considered here have been tested by means of the Box-Cox procedure, mainly with the aim of verifying the goodness of the log-transformation (for $\lambda=0$ ) and finding out exceptions to this rule $(\lambda \neq 0)$. In any case, the value $\lambda$ which maximizes the Likelihood Function:

$$
L=-\frac{v}{2} \ln s_{y^{\prime}}^{2}+(\lambda-1) \frac{v}{n} \sum \ln y
$$

gives rise to the best transformation to normality within the family of power transformations represented by the relationship: $y^{\prime}=\left(y^{\lambda}-1\right) / \lambda$.

In the above expression, $s_{y^{\prime}}{ }^{2}$ represents the variance of the transformed $y$ values $(y)$, based on $v=(n-1)=\operatorname{degrees}$ of freedom and $n=$ sample size. In the second term of the expression we have instead to calculate the sum of the natural logarithms of the original untransformed data $(y)$.

Due to the iterative procedure necessary to find $L_{\max }$, we have translated the algorithm by means of an appropriate basic language and evaluated by computer programme the related $\lambda$ value.

The same algorithm allows to estimate confidence limits to $\lambda$, at an assigned probability level. Taking into account that the quantity $-2 \times L_{\max }$ approximately follows the $\chi_{\alpha}{ }^{2}$ distribution (with 1 D.F.), solutions for upper and lover $\lambda$ confidence limits can be found from the pair of roots obtained by solving the Likelihood Function for:

$$
L=L_{\max }-\frac{1}{2} \chi^{2} \alpha
$$

Concerning the goodness of log-transformation applied to the TRIX original components, we observe in table 1 that $a D \% O$ sample distributions represent an evident exception to this rule. The corresponding $\lambda$ values are intermediate between 0 and 0.5 ( $\lambda=1 / 2$ is equivalent to the square root transformation). A more correct and suitable power transformation could be a double square root $\left(y^{\prime}=\sqrt[4]{y}\right.$, for $\left.\lambda=0.25\right)$. We have adopted however log-transformation for the $a D \% O$ data too, taking into account that "in most cases it makes sense to choose one or the other, rather than something in between" (Green 1979).

For parameters other than TRIX original components, log-transformation results appropriate for Secchi depth and for the Adriatic $F \%$ data, but not for the Tyrrhenian $F \%$ data, where $\lambda=-1.49$ would suggest something in the middle between the reciprocal transformation $(\lambda=-1)$ and the inverse square transformation $(\lambda=-2)$. Although the exact BoxCox power transformation was applied to these data, the resulting distributions did not give a satisfying approximation to the expected normal law. These difficulties are to be probably referred to the very large range of confidence evaluated for $\lambda$. By direct experience, we conclude that log-transformation applied to Dilution factor data distributions provides an acceptable approximation to the normality only if the annual range of variation is very large (at least 2 Log $_{10}$ units) and geometric averages of $F \%$ values are $\geq 5 \%$. This is the case of the Emilia Romagna coastal waters, due to the strong, but inconstant effect on the salinities coming from seasonal freshwater inputs of the Po River. The same effect on the $F \%$ data distributions was found for the Versilia coast in Tuscany (data not reported in table 1), directly affected by Arno River inputs.

Finally, the peculiar behaviour of the $\mathrm{P}-\mathrm{PO}_{4}$ data distributions has been already discussed in section 4.1.

\section{APPENDIX B}

\section{The multivariate context}

To provide a solid theoretical basis for the study of the variability, we have referred our analysis to a multivariate context: each variable, even though randomly distributed, is more or less affected by the other variables. In order to find and to assign a statistical significance to these interrelationships, that is to recognise a structure in the data, the Sphericity test of Bartlett (Bartlett 1954; Morrison 1978), was applied to the log-transformed data distributions. This test is aimed at verifying the significance of the correlation matrix $R$, by testing two hypotheses:

$$
\begin{array}{lll}
H_{0}: & R=I \text { (Identity matrix) } & \text { with } \operatorname{det}|R|=1 \\
H_{1}: & R \neq I & \text { with } \operatorname{det}|R| \neq 1
\end{array}
$$

The degree of interdependence among the variables is then associated to the natural logarithm of the correlation matrix determinant. Large significance differences with respect to the zero value $[\ln (1)=0]$, were always provided by 
the test, as a proof of the multidimensional structure of the data. After $\log _{10}$-transformation, each of the seven variables reported in table 1, results therefore approximately normally distributed as a marginal distribution of a unique multivariate distribution, with typical parameters represented by:

vector of the means: $\quad \bar{x}$

variance-covariance matrix: $S$

correlation matrix:

$S$
$R$

The assumption of multi-normality has been tested by means of the analysis of the Generalised Sample Distances:

$$
d_{i}=\sqrt{\left(x_{i}-\bar{x}\right)^{\prime} S^{-1}\left(x_{i}-\bar{x}\right)}
$$

where the expression under root represents a scalar, known as the Mahalanobis Distance (Mahalanobis 1936). In a Normal Probability graph paper, a visual examination of the good alignment of the $d_{i}$ data points along the straight line in the upper half of the diagram, allows the hypothesis of multi-normality to be verified (Legendre \& Legendre 1984), as e.g. in the diagrams of figure 12, related to the Livorno transect (Tuscany coastal waters) and to the Cattolica transect (Emilia Romagna coastal waters), where the normality of a $p$-dimensional sample (with $p=7$ previously log-transformed variables), can be reasonably accepted.
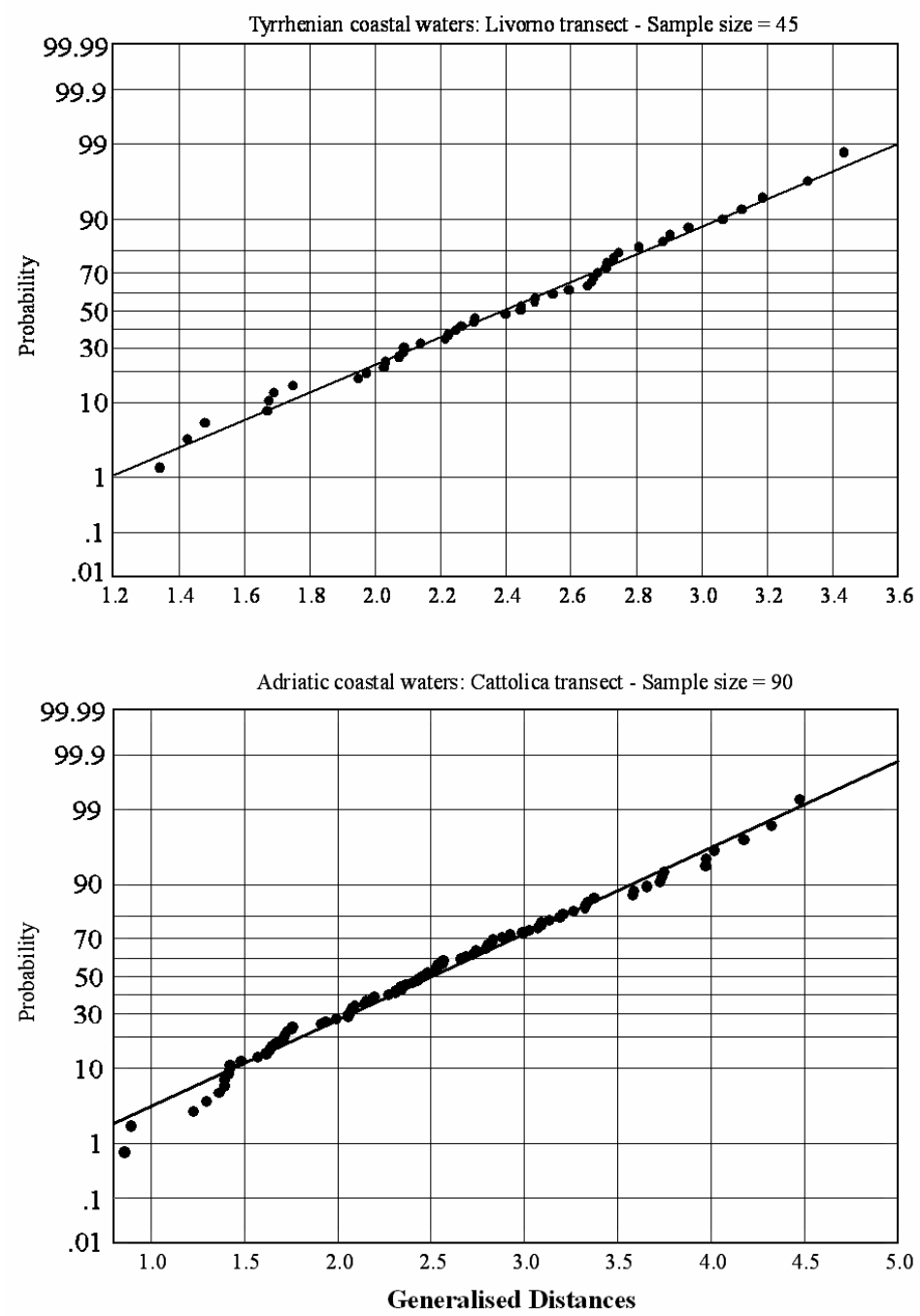

Fig. 12. Graphical results of a multi-normality test applied to a $p$-dimensional sample distributions. 


\section{APPENDIX C}

Statistical properties of the TRIX Index in relation to its components

In mathematical terms, the TRIX Index, as derived variable, recalls a linear additive function.

Rewriting the TRIX general formula (1) as a sum of logarithms:

$$
\text { TRIX Index }=\left(\log _{10}[\mathrm{ChA}]+\log _{10}[a D \% O]+\log _{10}[\operatorname{minN}]+\log _{10}[T P]+k\right) / m=Y
$$

by definition the mean of the linear compound $\mathrm{Y}$ will be:

$$
\bar{Y}=\left[\left(\sum_{i=1}^{4} \bar{X}\right)+k\right] / m
$$

where $\bar{X}$ represents the vector of the means of the original log-transformed variables.

Taking into account the concept of structure within the data, as shown in Appendix B, we evaluate the variance of a derived variable $Y$, as:

$$
\operatorname{var}(Y)=a^{\prime} \sum a=\sum \sum a_{i} a_{j} \cdot \sigma_{i, j}
$$

where $\Sigma$ is the covariance matrix, $a^{\prime}$ and $a$ the vectors-row and column of the coefficients of the linear additive function, $\sigma_{i, j}$ are the terms of the covariance matrix, with the convention that, if $i=j$, then $\sigma_{i, j}=\sigma_{x_{i}}^{2}$.

$\operatorname{Var}(Y)$ is therefore comprehensive of the share of variation expressed by the single variables (variances), plus the share due to the co-variation (covariances) (Morrison 1978).

In the TRIX formulation, the shift of $k=1.5$ on the original variates, by definition does not affect the variances. By adapting the equation (19) to TRIX index, we obtain therefore:

$$
\operatorname{var}(Y)=m^{-2} \sum_{i=1}^{4} \sum_{j=1}^{4} \sigma_{i, j}=\operatorname{var} \operatorname{TRIX}
$$

The parameter $m=1.2$, introduced with the aim of properly scaling TRIX Index, modifies the variances by a factor $m^{-2}=0.694$, in such a way that the whole variability (i.e. var TRIX) has been reduced by nearly $30 \%$, with respect to the initial variability expressed by single log-components, both in terms of variances and covariances.

\section{APPENDIX D}

Cartesian diagrams of the system main parameters (Innamorati \& Giovanardi 1992)

With a complete annual cycle of data for a given sea area, the bivariate distributions of $\log \left(\operatorname{ChA} / \mathrm{PO}_{4}\right)$ and $\log (C h A / D I N)$ will result close to the normal kind. If the slope $k$ of the orthogonal regression equation:

$$
\log \left(\mathrm{ChA} / \mathrm{PO}_{4}\right)=\log b+k \log (\mathrm{ChA} / \mathrm{DIN})
$$

tends to one, the system reaches the isometry along the $45^{\circ}$ line. We can then replace the logarithms with the numbers and we obtain:

$$
\left(C h A / P O_{4}\right)=b(C h A / D I N)^{k}
$$

Being $k=1$, it will be:

$$
D I N / P O_{4}=N / P=b
$$

In a similar way, along the $-45^{\circ}$ line $(k=1)$, the system gives rise to:

$$
(\mathrm{ChA})^{2}=b\left(\mathrm{DIN} \cdot \mathrm{PO}_{4}\right)
$$

from which:

$$
C h A / \sqrt{\left(D I N \cdot P O_{4}\right)}=\text { constant }
$$

By plotting $\log \left(\mathrm{ChA}_{\mathrm{P}} \mathrm{PO}_{4}\right)$ and $\log (\mathrm{ChA} / \mathrm{DIN})$ data points on a Cartesian diagram (see Fig. 10), we are able to make distinction among different space-time situations related to nutrients limitation and/or to their utilisation by the system. TRIX per se does not make distinction of this sort, therefore the derived indices examined and proposed here, are to be considered as supplementary tools to the TRIX use. 


\section{REFERENCES}

Bartlett, M.S. 1954. A note on the multiplying factors for various chi-square approximations. J. Roy. Stat. Doc., B 16: 296-298.

Box, G.E.P. \& D.R. Cox. 1964. An analysis of transformations. J. Roy. Stat. Soc., Ser. B, 26: 211-243.

Bukata, R.P., J.H. Jerome, K.Y. Kondratyev \& D.V. Pozdnyakov. 1995. Optical Properties and Remote Sensing of Inland and Coastal Waters. CRC Press: 362 pp.

Cicero, A.M., C.R. Ferrari, F. Giovanardi, E. Magaletti, C. Mazziotti, A. Ghetti, G. Montanari, A. Rinaldi, A. Scarpato \& E. Romano. 2001. Applicazione dell'Indice Trofico (TRIX) in aree tirreniche ed adriatiche ai fini della classificazione delle acque marine costiere. Biol. Mar. Medit., 8(1): 648-653.

Denman, K.L. \& E. Gargett. 1983. Time and space scales of vertical mixing and advection of phytoplankton in the upper ocean. Limnol. Oceanogr., 28(5): 801-815.

Fausch, K.D., J. Lyons, J.R. Karr \& P.L. Angermeier. 1990. Fish communities as indicators of environmental degradation. American Society Symposium, 8: 123-144.

Giovanardi, F. \& E. Tromellini. 1992a. Statistical Assessment of Trophic Conditions. Application of the OECD Methodology to the Marine Environment. Proc. Int. Conf. Marine Coastal Eutrophication. Sci. Total Environ., Suppl. 1992: 211-233.

Giovanardi, F. \& E. Tromellini. 1992b. An empirical dispersion model for total phosphorus in a coastal area: the Po River-Adriatic system. Proc. Int. Conf. Marine Coastal Eutrophication. Sci. Total Environ, Suppl. 1992: 201210.

Green, R.H. 1979. Sampling Design and Statistical Methods for Environmental Biologists. A Wiley-Interscience Publication. John Wiley \& Sons-New York: 257 pp.

Harris, G.P. 1986. Phytoplankton Ecology. Structure Function and Fluctuations. Chapman and Hall: $384 \mathrm{pp}$

Innamorati, M. \& F. Giovanardi. 1992. Interrelationships between phytoplankton biomass and nutrients in the eutrophied areas of the Northwestern Adriatic Sea. Proc. Int. Conf. Marine Coastal Eutrophication. Sci. Total Environ., Suppl. 1992: 235-250.

Innamorati, M. 1989. Proprietà statistiche e processi di rinnovo dei nutrienti e del fitoplancton in mare. Oebalia, XV-1: 357-374.

Legendre, L. \& P. Legendre. 1984. Écologie numerique. 1. Le traitement des données écologiques. 2. La structure des données écologiques. Masson-Presse de l'Université du Quebec; deuxième édition : $1^{\circ}$ Vol. 260 pp. $2^{\circ}$ Vol. $335 \mathrm{pp}$.

Mahalanobis, P.C. 1936. On the generalized distance in statistics. Proc. Natl. Sci. India, 12: 49-55.

Margalef, R., 1965. Ecological correlations and the relationship between primary productivity and community structure. Mem. Ist. ital. Idrobiol., Suppl. 18: 355-364.

Ministero dell'Ambiente (Servizio Difesa Mare) \& ICRAM (Istituo Centrale per la Ricerca Applicata al Mare), ROMA. 2000. Qualità degli ambienti marini costieri italiani: 1996-1999. Valutazione preliminare del monitoraggio realizzato in convenzione con le regioni costiere: $272 \mathrm{pp}$.

Received: August 2004

Accepted: September 2004
Morrison, D.F. 1976. Multivariate Statistical Methods. 2nd Edition. McGraw-Hill: 415 pp.

Officer, C.B. 1976. Physical Oceanography of Estuaries (and Associated Coastal Waters). J.Wiley \& Sons, New York: $324 \mathrm{pp}$.

Platt, T. 1981a. Thinking in terms of scale: introduction to dimensional analysis. In: Mathematical models in biological oceanography. The UNESCO Press. Paris: 157 pp.

Platt, T. 1981b. General conclusions. In: Mathematical models in biological oceanography. The UNESCO Press. Paris: $157 \mathrm{pp}$.

Reynolds, C.S. \& S.C. Maberly. 2002. A simple method for approximating the supportive capacities and metabolic constraints in lakes and reservoirs. Freshwat. Biol., 47(6): 1183-1188.

Siegel, S. \& N.J. Castellan Jr. 1992. Statistica non parametrica. (Original title: Nonparametric Statistics for the Behavioral Sciences). McGraw-Hill Libri Italia, Milano: $447 \mathrm{pp}$.

Sokal, R. R. 1973. Introduction to biostatistics. W.H. Freeman. San Francisco: 368 pp

Sokal, R.R. \& F.J. Rohlf. 1995. Biometry - The Principles and Practice of Statistics in Biological Research. 3rd edition. W.H. Freeman \& Co. New York: 887 pp.

U.S. Environmental Protection Agency. 1994. Biological criteria.- Technical guidance for streams and small rivers. Washington D.C. U.S. Environmental Protection Agency, Office of Water, EPA 822-B-94-001: 162 pp.

Vollenweider, R.A. 1968. Scientific fundamentals of the eutrophication of lakes and flowing waters, with particular reference nitrogen and phosphorus as factors in eutrophication. O.E.C.D., Paris. Tech. Report DA 5/SCI/68.27: $250 \mathrm{pp}$.

Vollenweider, R.A. 1976. Advances in defining critical loading level for phosphorus in lake eutrophication. Mem. Ist. ital. Idrobiol., 33: 53-83.

Vollenweider, R.A. \& J.J. Kerekes (Eds). 1982. Eutrophication of Waters, Monitoring, Assessment and Control. O.E.C.D. Paris: 154 pp.

Vollenweider, R.A., A. Rinaldi \& G. Montanari. 1992. Eutrophication, structure and dynamics of a marine coastal system: results of a ten years monitoring along the Emilia-Romagna coast (Northwest Adriatic Sea). Proc. Int. Conf. Marine Coastal Eutrophication. Sci. Total Environ., Suppl. 1992: 63-106.

Vollenweider, R.A., F. Giovanardi, G. Montanari \& A. Rinaldi. 1998. Characterization of the trophic conditions of marine coastal waters, with special reference to the NW Adriatic Sea: proposal for a trophic scale, turbidity and generalized water quality index. Environmetrics, 9: 329357.

Ward, C.R., J.C. Loftis \& G.B. McBride. 1990. Design of Water Quality Monitoring Systems. Van Nostrand Reinhold, New York: $231 \mathrm{pp}$.

Yentsch, C.S. 1975. New England coastal waters: an infinite estuary. In: Marine Chemistry in the Coastal Environment. American Chemical Soc. Philadelphia, Penn. ACS Symposium-Series 18.

Zurlini G. 1996. Multiparametric classification of trophic conditions. The OECD methodology extended: combined probabilities and uncertainties - application to the North Adriatic Sea. Sci. Total Environ., 182(1-3): 169-185. 